\title{
Revision of Ganomymar De Santis, 1972, a remarkable genus of Mymaridae (Hymenoptera, Chalcidoidea) from Madagascar
}

\author{
Serguei V. TRIAPITSYN \\ Entomology Research Museum, Department of Entomology, University of California, Riverside, \\ California, 92521, USA. \\ Email: serguei.triapitsyn@ucr.edu \\ (1) https://orcid.org/0000-0002-5086-7847
}

urn:1sid:zoobank.org:author:142EB501-A905-44BF-8179-96EA8C8C7818

\begin{abstract}
A rare fairyfly (Hymenoptera, Mymaridae) genus, Ganomymar De Santis, 1972, is revised and rediagnosed based on both sexes; its males were previously unknown. This genus, which has remarkable structures on the propodeum and peculiar fore wings in females, is known only from Madagascar in the Afrotropical region. Its type species, Ganomymar dessarti De Santis, 1972, is redescribed and illustrated based on a non-type female specimen. Three new species of Ganomymar are described: G. caslot sp. nov., G. libertatium sp. nov., and G. zuparkoi sp. nov. The species are placed in two distinct species groups. A key to females of the four species is provided.
\end{abstract}

Kewords. Mymaridae, fairyfly, biodiversity, Afrotropical region, Madagascar.

Triapitsyn S.V. 2021. Revision of Ganomymar De Santis, 1972, a remarkable genus of Mymaridae (Hymenoptera, Chalcidoidea) from Madagascar. European Journal of Taxonomy 757: 127-151. https://doi.org/10.5852/ejt.2021.757.1417

\section{Introduction}

The fauna of Mymaridae (Hymenoptera: Chalcidoidea), commonly known as fairyflies, of Madagascar is particularly interesting and diverse. Although mostly Afrotropical, Madagascar has several endemic genera in the Polynema Haliday genus group. Most of them are still undescribed, but one, a rare genus Ganomymar De Santis, 1972, was previously known from a single female specimen, the holotype of its type species Ganomymar dessarti De Santis, 1972. There has been no other mention of Ganomymar in the taxonomic literature since its original description. Ganomymar appears to be quite rare: despite the more recent collection of thousands of fairyfly specimens from Madagascar, only a few were found among the $95 \%$ ethanol-preserved samples of Mymaridae sorted to family by Robert L. Zuparko at the California Academy of Sciences, San Francisco, USA. Among them, I identified one female G. dessarti and three previously unknown species, which are described. Two of these new species are represented by both sexes; the previously unknown males of Ganomymar are also described and illustrated, displaying a remarkable sexual dimorphism in one of them. A key to females of the four species is given. 


\section{Material and methods}

\section{Institutional abbreviations}

CAS = California Academy of Sciences, San Francisco, California, USA

RBINS $=$ Royal Belgian Institute of Natural Sciences, Brussels, Belgium

UCRC $=$ Entomology Research Museum, Department of Entomology, University of California, Riverside, California, USA

\section{Abbreviations for morphological terms \\ $\mathrm{F} \quad=$ funicular segment of the female antenna or flagellomere of the male antenna \\ mps $=$ multiporous plate sensillum or sensilla on the antennal flagellar segments (= longitudinal sensillum or sensilla or sensory ridge(s) of other authors)}

Specimens were critical point dried from 95\% ethanol, point-mounted, and labeled. Selected specimens were then dissected and slide-mounted in Canada balsam after their habitus digital images had been taken using an Auto-Montage system by Syncroscopy. Terms used for morphological features are mostly those of Gibson (1997). All measurements of the primary types were taken from the slide-mounted specimens, unless stated otherwise, and are given in micrometers $(\mu \mathrm{m})$, as length or, for the wings, as length:width.

\section{Results}

Class Insecta Linnaeus, 1758

Order Hymenoptera Linnaeus, 1758

Suborder Apocrita Gerstaecker, 1867

Superfamily Chalcidoidea Latreille, 1817

Family Mymaridae Haliday, 1833

Genus Ganomymar De Santis, 1972

Figs 1-15

Ganomymar De Santis, 1972: 1-2 (type species: Ganomymar dessarti De Santis, 1972, by original designation).

\section{Diagnosis}

\section{Both sexes}

Vertex with a small pit-like depression next to each ocellus (Fig. 2C). Face without a pit next to each torulus. Mandible 3-dentate. Radicle very short, fused with the rest of scape. Pronotum entire; prosternum separated from head by propleura abutting each other anteriorly, and incompletely divided by a weak, short carina posteriorly; mesoscutum wider than long, with fairly wide notaular grooves ending anteriorly in small pits; scutellum separated posteriorly from frenum by transverse row of small foveae, and with campaniform sensilla closer to posterior margin than to anterior margin and very close to each other; frenum short, $0.2-0.33 \times$ length of scutellum; propodeum at posterior margin with a pair of small white puffs (spherical structures of unknown nature that are very translucent and thus not visible in slide-mounted specimens) on both sides of petiole attachment (best seen in dry-mounted specimens, Figs 7A, 10B). Tarsi 4-segmented. Petiole attached posteriorly to gastral sternum.

\section{Female}

Antenna (Figs 2D, 6E, 8D, 14B) 9-segmented (funicle 6-segmented), with scape notably compressed laterally and smooth; F1 the shortest and F2 the longest funiculars and F3 the second longest, all 6 funiculars without mps; clava large, entire, with $6 \mathrm{mps}$ arranged as follows: 2 about in the middle, and 
2 subapical pairs. Macropterous or brachypterous. Ovipositor not or at most barely exserted beyond apex of gaster.

\section{Male}

Antenna (Figs 5C, 11A) much longer than body, 13-segmented (flagellum 11-segmented), with all flagellomeres much longer than wide and each with several mps. Macropterous. Digiti of genitalia (Figs 5B, 12B) without denticles apically.

\section{The caslot species group}

Both sexes macropterous (Figs 1, 3A, 4, 5D, 13, 14E); mesosoma (Figs 2E, 3B, 14D) smooth, with pronotum not enlarged and propodeum either without carinae or with a short median carina extending from posterior margin for at most half length.

\section{The dessarti species group}

Females brachypterous (Figs 6A-B, 7C-D, 9A-B) and males macropterous (Figs 10A, 12A); propodeum in both sexes with prominent submedian carinae (Figs 6D, 7A, 8C, 11C); female mesosoma at least partially reticulate (Figs 6D, 8B-C, E), with pronotum notably enlarged; male mesosoma (Fig. 11B-C) mostly smooth, with pronotum not enlarged.

\section{Remarks}

Ganomymar belongs to the Polynema Haliday, 1833 genus group, as defined by Lin et al. (2007). Its relationships to other members of the group are unclear, and without having any genetic evidence, it would be premature to make an educated guess. The genus has a unique feature, the propodeum with a pair of small white puffs at posterior margin at both sides of the petiole attachment in both sexes. This feature, and the peculiar fore wings, particularly in females, separates Ganomymar from all other members of the Polynema genus group. The four known species are placed in two distinct, informal species groups (two species in each), as defined above. The males (known only for one species in each group) are quite similar morphologically except for the markedly different configuration of the propodeal carina(e) in both sexes. That is quite unusual for the Polynema genus group in which presence or absence and the configuration of propodeal carina(e) when present, are often important diagnostic features used to distinguish the genera. This variability in propodeal carinae also occurs in species of Cremnomymar Ogloblin, 1952 (Mymaridae) from Juan Fernández Islands, Chile (Huber 2013).

\section{Hosts and biology}

Unknown.

\section{Distribution}

Afrotropical region: Madagascar.

\section{Key to species of Ganomymar (females)}

1 Mesosoma at least partially reticulate (Figs 6D, 8B-C, E), with pronotum notably enlarged and propodeum with prominent submedian carinae (Figs 7A, 8C); brachypterous (Figs 7C-D, 9A-B) (dessarti species group)

- Mesosoma smooth (Figs 2E, 14D), with pronotum not enlarged and propodeum either without carinae or with a short median carina extending from posterior margin for at most half length (Fig. 2E); macropterous (Figs 3A, 14E) (caslot species group)

2 Head dark brown to black (Fig. 6A-B), vertex smooth (Fig. 6C); rest of body mostly light brown (Fig. 6A-B); fore wing narrow, without 'cells' beyond venation (Fig. 7C)

G. dessarti De Santis, 1972 
- Head mostly pale yellow (Fig. 9C), vertex with reticulate sculpture (Fig. 8B); rest of body mostly yellow (Fig. 9C); fore wing wide, with numerous round 'cells' beyond venation (Fig. 9A)

G. libertatium sp. nov.

3 Clava white, contrastingly lighter than funicle (Figs 1A, 2D), F2 about $6 \times$ as long as wide; fore wing (Fig. $3 \mathrm{~A}$ ) with longest marginal seta at most $0.85 \times$ greatest width of wing

- Clava brown, contrastingly darker than funicle (Figs 13B, 14B), F2 about $11 \times$ as long as wide; fore wing (Fig. 14E) with longest marginal seta about $1.1 \times$ greatest width of wing

G. zuparkoi sp. nov.

\section{Ganomymar caslot $\mathrm{sp}$. nov. \\ urn:Isid:zoobank.org:act:F364774F-6D86-4DC1-BBAE-AEBBD0D14C03}

Figs $1-5$

\section{Diagnosis}

Ganomymar caslot is a member of the caslot species group. Females differ from the other species of this group, G. zuparkoi, by the diagnostic features given in the key.

\section{Etymology}

The species epithet is a noun in apposition referring to CAS LOT [California Academy of Sciences, lot number] numbers on the specimens borrowed from CAS.

\section{Type material}

\section{Holotype}

MADAGASCAR • + (on slide, complete and dissected under 4 coverslips) [Fig. 2A]; Vatovavy-Fitovinany Region [formerly within Fianarantsoa Province], Ranomafana National Park; "MADAGASCAR: Prov.

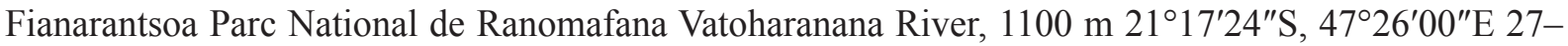
31.iii.2003, [B.L.] Fisher, [T.L.] Griswold et al., pitfall trap in montane rainfor[est] BLF8402, CAS LOT \# 009546", "Mounted at UCR/ERM by V. V. Berezovskiy 2004 in Canada balsam", [red] "Ganomymar caslot Triapitsyn HOLOTYPE O", "Det. by S. V. Triapitsyn 2012", [a small red circle indicative to a number of someone's digital image(s)], "016a"; CAS.

\section{Paratypes}

MADAGASCAR - 1 (on point); same locality data as for holotype; "MADAGASCAR: Prov.

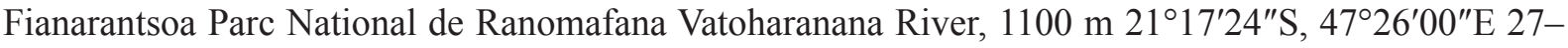
31.iii.2003, [B.L.] Fisher, [T.L.] Griswold et al., pitfall trap in montane rainfor[est] BLF8402, CAS LOT \# 009546"; CAS • 1 q (on point), same collection data as for preceding; UCRC • 1 q (on slide), 1 ㅇ (on point); same locality data as for preceding; "MADAGASCAR: Prov. Fianarantsoa Parc National de Ranomafana Vatoharanana River, $1100 \mathrm{~m} 21^{\circ} 17^{\prime} 24^{\prime \prime} \mathrm{S}, 4^{\circ} 26^{\prime} 00^{\prime \prime} \mathrm{E} 27-31 . i i i .2003$, [B.L.] Fisher, [T.L.] Griswold et al., YPT in montane rainforest BLF8399, CAS LOT \# 011175"; UCRC • 1 (on point); Vatovavy-Fitovinany Region [formerly within Fianarantsoa Province], Ranomafana National Park; "MADAGASCAR: Prov. Fianarantsoa Parc National Ranomafana $1130 \mathrm{~m}, 21^{\circ} 15.05^{\prime} \mathrm{S}, 4^{\circ} 24.43^{\prime} \mathrm{E}$ 7-17.v.2003, R. Harin'Hala, MT MA-02-09B-60, CAS LOT \# 016339”; CAS • 1 q (on slide); AtsimoAtsinanana Region (formerly within Fianarantsoa Province), Midongy du Sud (also known as MidongyBefotaka or Befotaka-Midongy) National Park; "MADAGASCAR: Fianarantsoa Prov. Parc National Befotaka-Midongy Papango, 1250 m, MT 2350'27"S, 46 57'27"E 17-19.xi.2006, B.[L.] Fisher et al. BLF14944, CAS LOT \# 035001"; CAS • 1 ○ (on slide); same collection data as for preceding; UCRC - $1 \hat{\sigma}$ (on point); same collection data as for preceding; CAS $\bullet 1$ (on slide); Anosy Region [formerly 


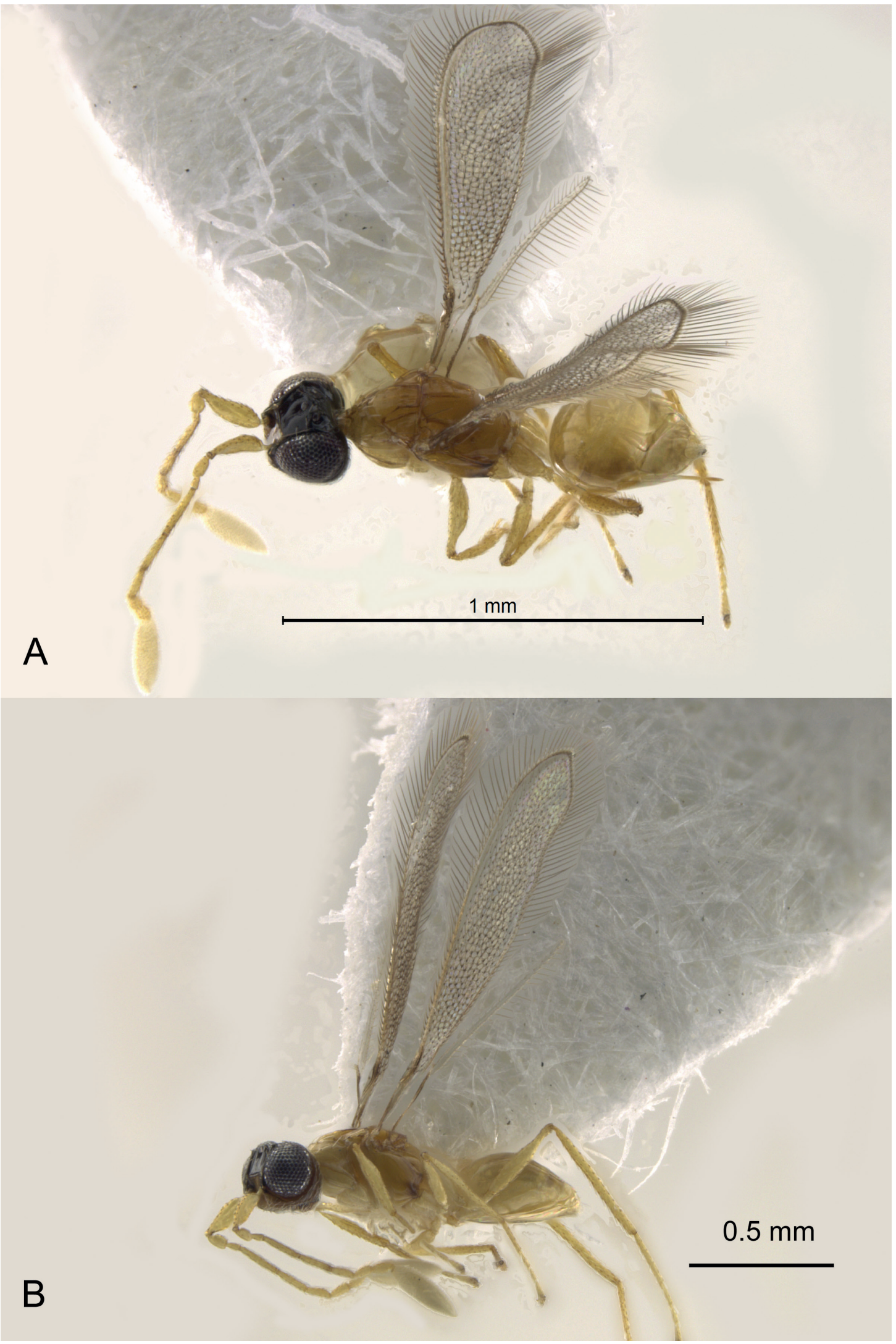

Fig. 1. Ganomymar caslot sp. nov. A. + , paratype (CASENT 2079162), habitus in dorsolateral view. B. , paratype (CASENT 2079174), habitus in lateral view. 

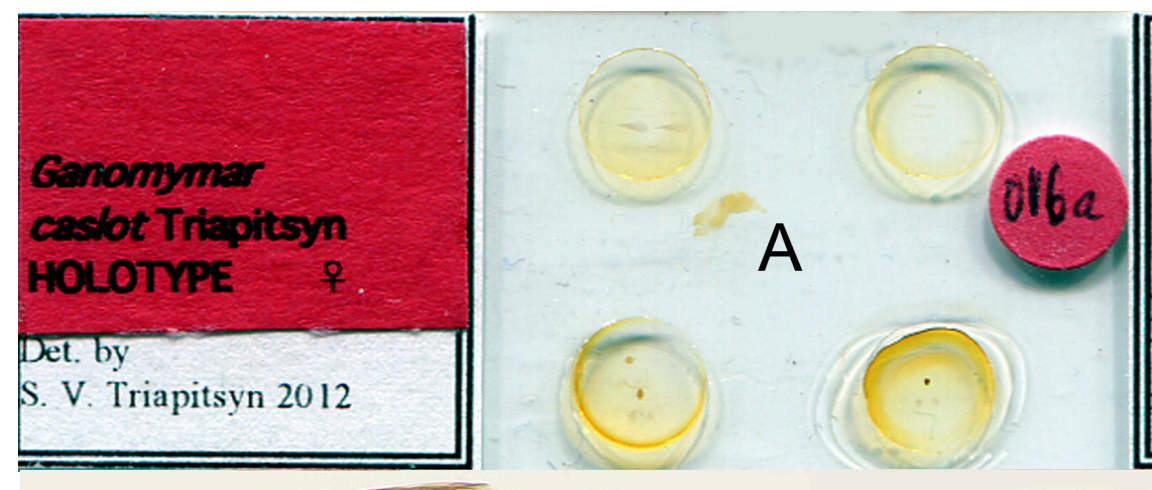

MADAGASCAR: Prov. Fianarantsoa

Parc National de Ranomatana

Vatoharanana River. $1100 \mathrm{~m}$

$21^{\circ} 17^{\prime} 24^{\prime}$ S. $47^{\circ} 26^{\circ} 00^{\prime \prime} \mathrm{E}$

27 31, iï.2003, Fisher, Griswold

et al., pitiall trap in montane raintor B!F8402. CASLOT \#009546

Mounted at UCR/ERM by

V. V. Berezovskiy 2004

in Canada balsam
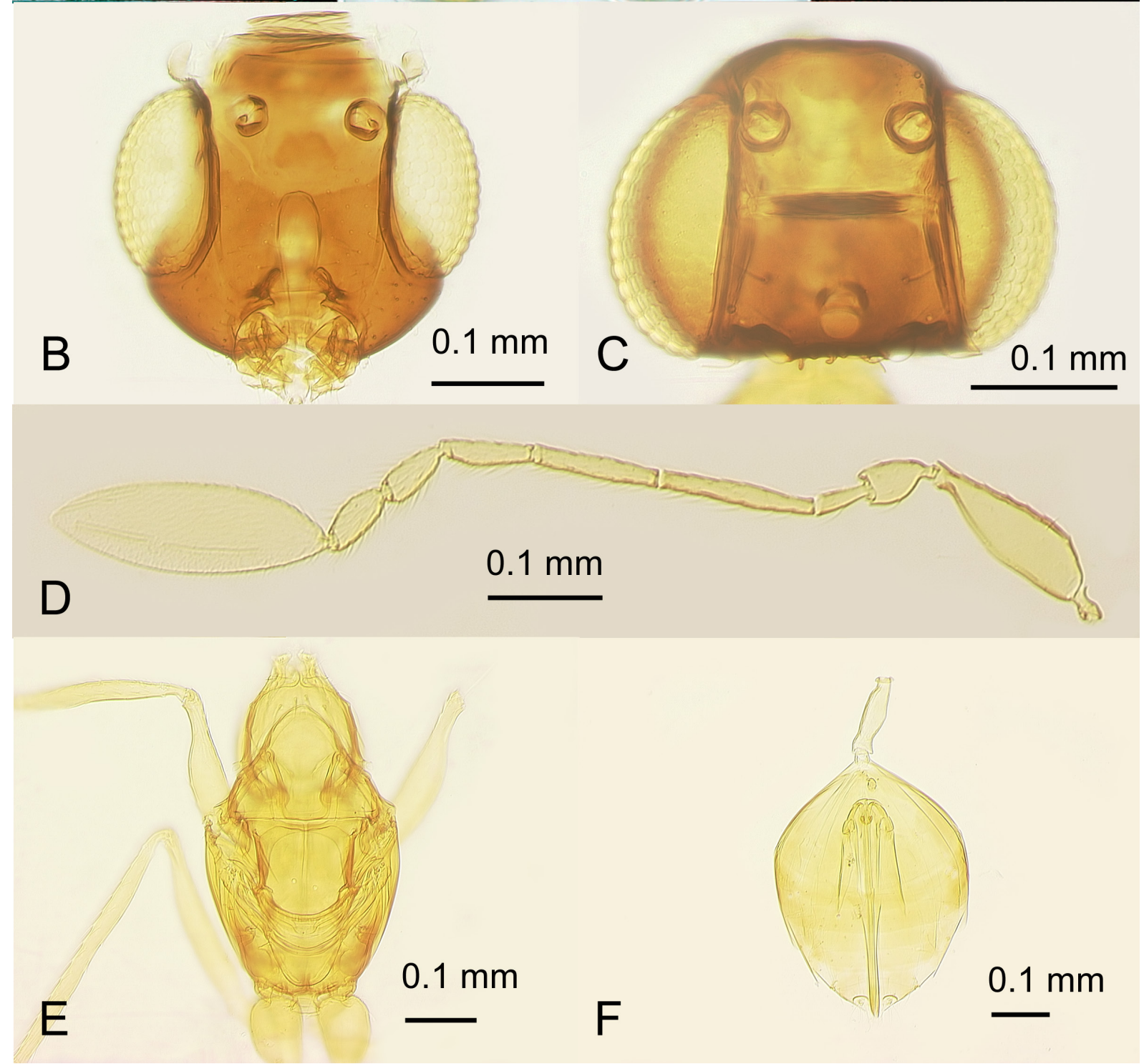

Fig. 2. Ganomymar caslot sp. nov., . . A. Holotype slide. B. Head in frontal view, holotype (CAS). C. Head in dorsal view, paratype (CASENT 2079164). D. Antenna, holotype (CAS). E. Mesosoma, holotype (CAS). F. Metasoma, holotype (CAS). 


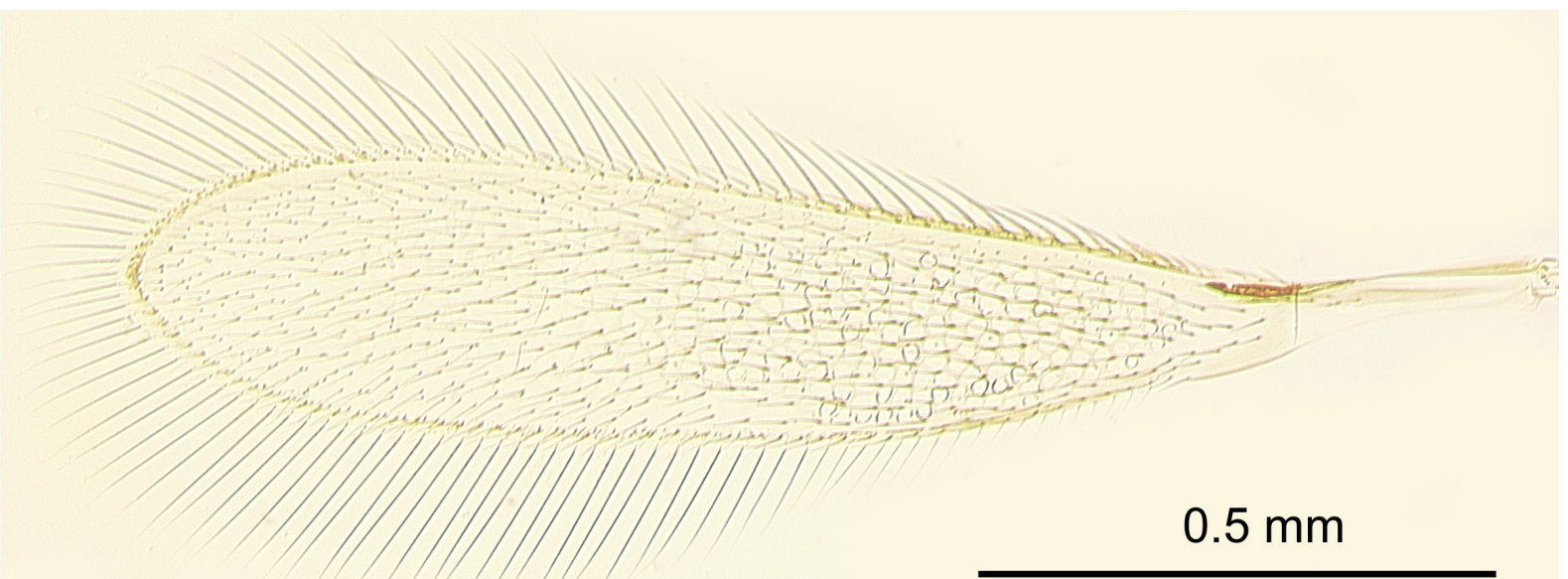

A

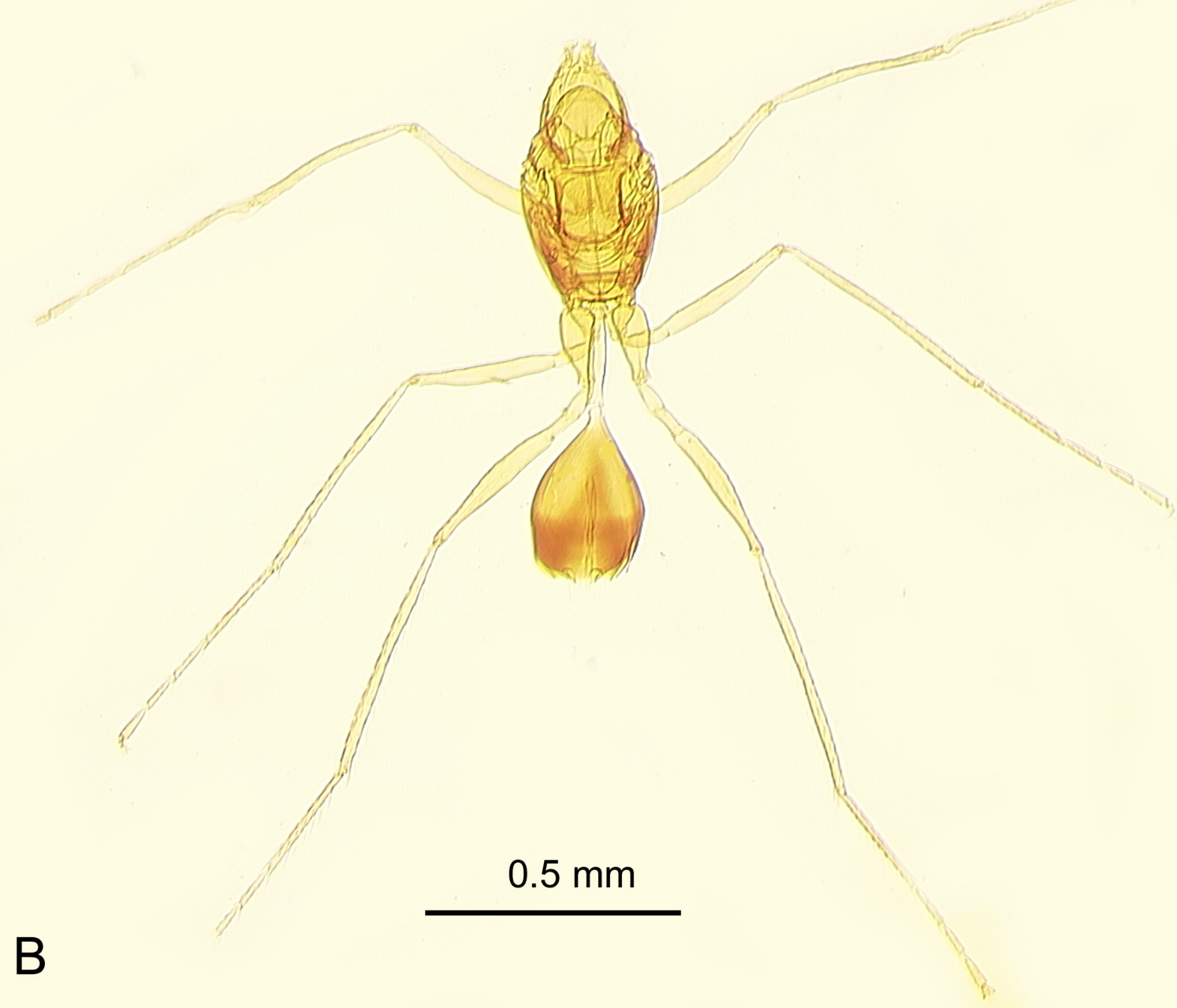

Fig. 3. Ganomymar caslot sp. nov. A. Fore and hind wings, $q$, holotype (CAS). B. Mesosoma, metasoma and legs, $\hat{o}$, paratype (CASENT 2079167). 
within Toliara Province], Andohahela National Park; "MADAGASCAR Toliara Prov. Parc National

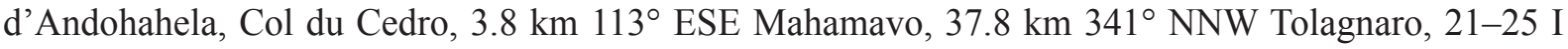
$20022^{\circ} 45^{\prime} 50^{\prime \prime} \mathrm{S} 46^{\circ} 45^{\prime} 6^{\prime \prime} \mathrm{E}$ coll. [B.L.] Fisher, [T.L.] Griswold et al. California Academy of Sciences pitfall trap - montane rainforest elev 900m code BLF5013", "CASLOT \# 008196"; CAS • 1 क (on point); same locality as for preceding; "MADAGASCAR Toliara Prov. Parc National d'Andohahela,

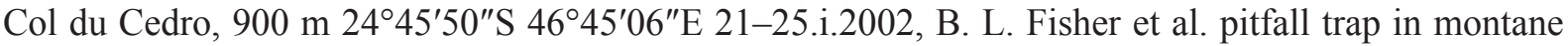
rainforest CAS LOT \# 008196, BLF5013"; UCRC.

\section{Description}

Female (holotype)

COLOR. Head black except face dark brown, rest of body (as in the paratype, Fig. 1) mostly light brown, the mesosoma, except pronotum, slightly darker than pronotum and metasoma; appendages mostly light brown except clava white.

Head (Fig. 2B). Slightly wider than high, $1.2 \times$ as wide as mesosoma; face smooth, with fine, inconspicuous setae below toruli, the latter raised above face surface and projecting slightly forward in dorsal view; vertex smooth and with 4 or 5 pairs of longer setae; occiput with 2 pairs of longer setae.

Antenna (Fig. 2D). Scape, excluding radicle, $3.1 \times$ as long as wide; pedicel smooth, longer than F1 and $1.8 \times$ as long as wide; F5 as long as F6, length to width ratios of funiculars: $\mathrm{F} 1=2.3, \mathrm{~F} 2=6.1 ; \mathrm{F} 3=4.2$;

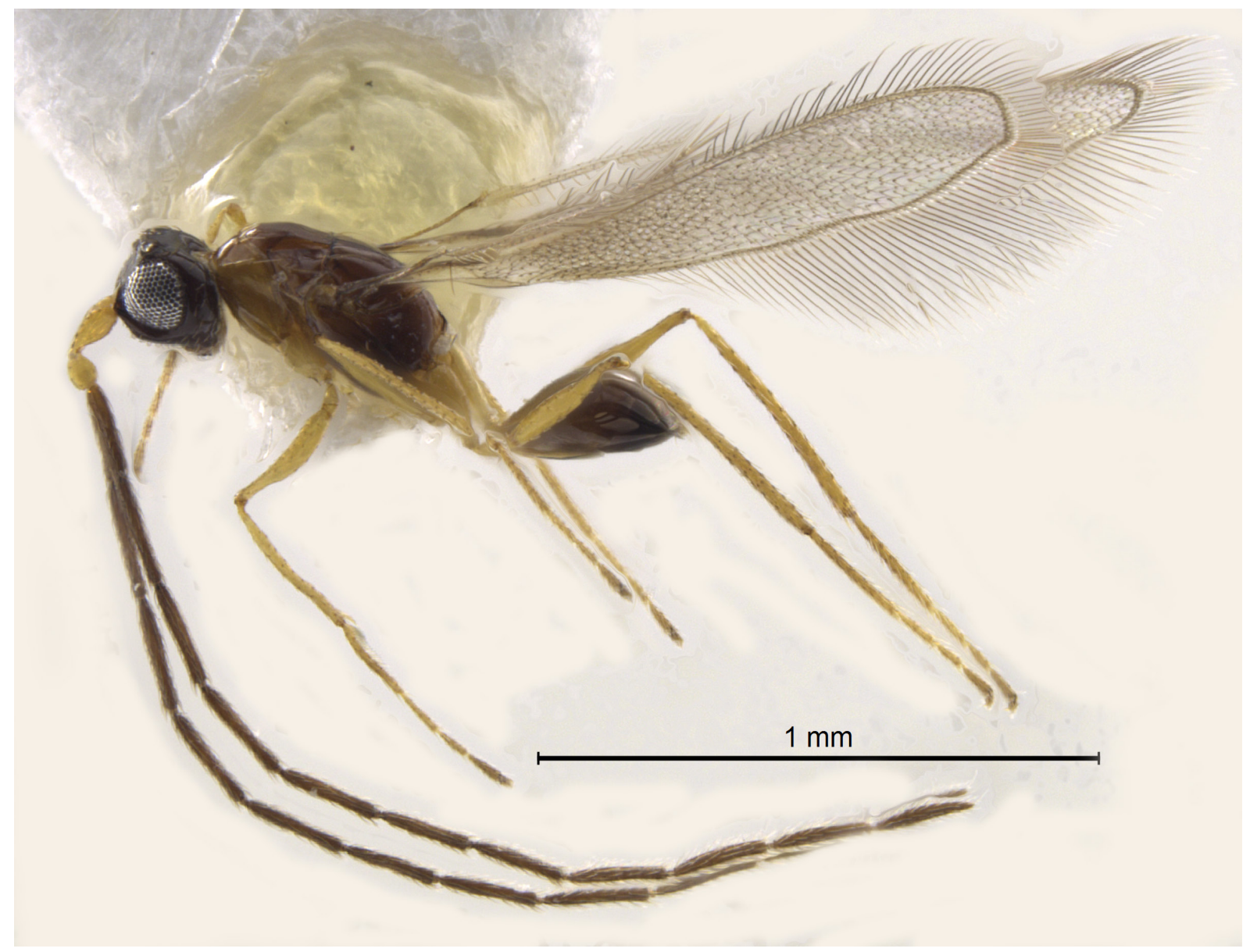

Fig. 4. Ganomymar caslot sp. nov., ô, paratype (CASENT 2079171), habitus in lateral view. 
$\mathrm{F} 4=2.4 ; \mathrm{F} 5=2.2 ; \mathrm{F} 6=2.6$; clava $3.0 \times$ as long as wide, longer than combined length of 3 preceding flagellomeres.

Mesosoma (Fig. 2E). Smooth, about $1.9 \times$ as long as wide; pronotum with 2 pairs of strong setae at posterior margin; axillar seta $0.078 \mathrm{~mm}$ long, extending to campaniform sensilla; scutellum + frenum as long as mesoscutum, scutellum divided mediolongitudinally by a shallow groove; propodeum with a short median carina extending from posterior margin for about half length.
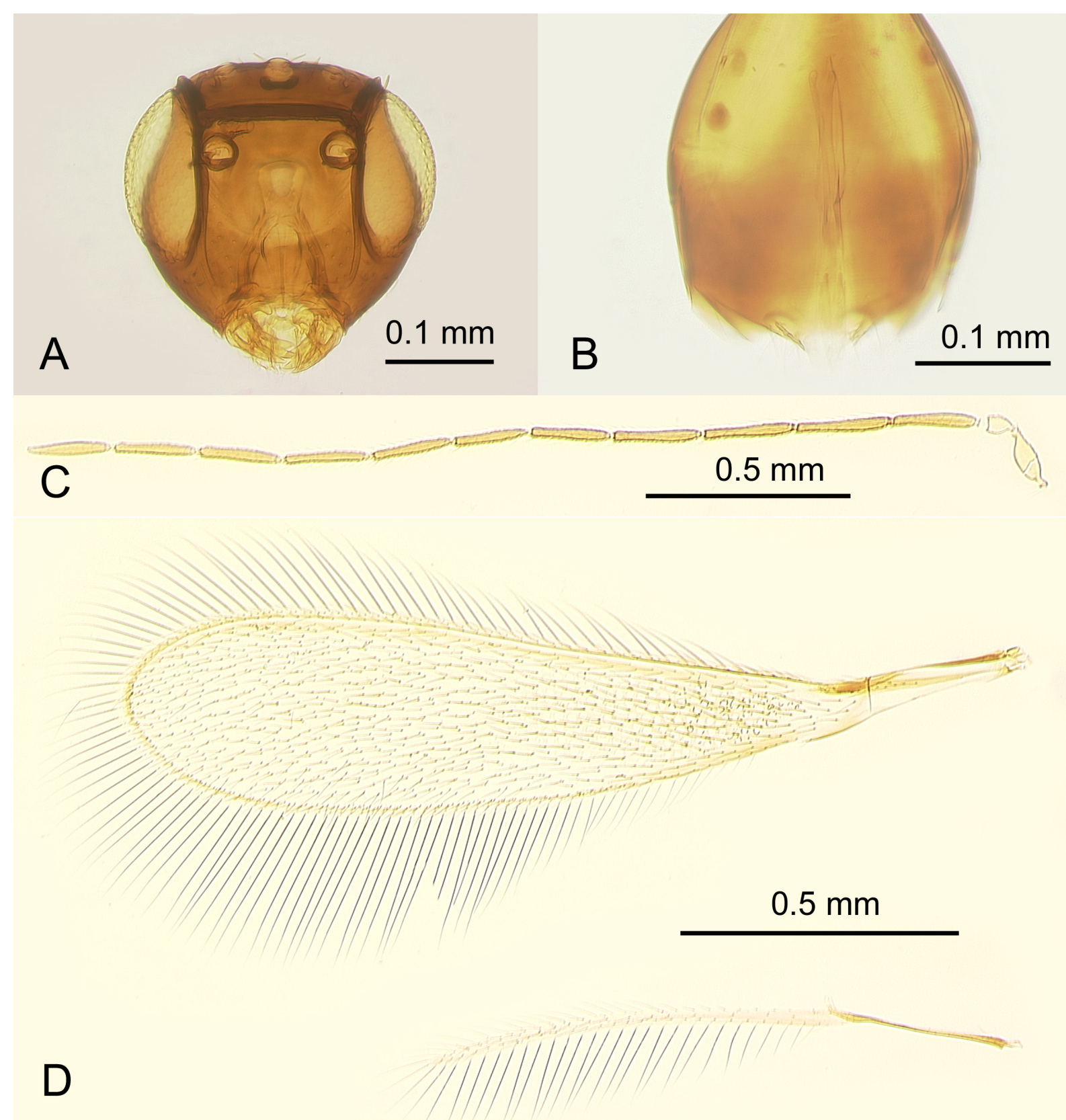

Fig. 5. Ganomymar caslot sp. nov., Õ, paratype (CASENT 2079167). A. Head in frontal view. B. Genitalia. C. Antenna. D. Fore and hind wings. 
Wings. Macropterous. Fore wing (Fig. 3A) $5.1 \times$ as long as wide; marginal vein with 1 dorsal macrochaeta; disc notably infumate, densely setose beyond venation, the discal setae originating behind apex of submarginal vein, with numerous round 'cells' beyond venation particularly conspicuous up to about $0.6 \times$ length of wing and then gradually fading towards apex so not visible at wing apex; longest marginal seta $0.85 \times$ greatest width of wing, proximal fringe setae on anterior margin stronger than other fringe setae. Hind wing (Fig. 3A) about $35 \times$ as long as wide; disc slightly infumate, with 2 rows of setae; longest marginal seta $2.4 \times$ greatest width of wing.

LEGS. All legs smooth, metacoxa with dense white setae.

Metasoma. Petiole (Fig. 2F) smooth, $3.4 \times$ as long as wide and slightly swollen medially, about as long as metacoxa. Ovipositor $0.8 \times$ length of gaster (Fig. $2 \mathrm{~F}$ ), not exserted beyond its apex, about as long as mesotibia and about $0.8 \times$ length of metatibia.

MeAsurements $(\mu \mathrm{m})$. Mesosoma $=492 ;$ mesoscutum $=154 ;$ scutellum $=154 ;$ petiole $=70$; gaster $=455$; ovipositor $=370$. Radicle $=30$; rest of scape $=179$; pedicel $=66 ; \mathrm{F} 1=45 ; \mathrm{F} 2=148 ; \mathrm{F} 3=124 ; \mathrm{F} 4=88$; F5 $=66 ; \mathrm{F} 6=66$; clava $=267$. Fore wing $=1396: 276$; venation $=326$; longest marginal seta $=234$. Hind wing $=940: 27$; longest marginal seta $=66$. Mesotibia $=375 ;$ metatibia $=443$.

\section{Variations}

Female (paratypes)

MeAsurements. Body length (critical point dried specimens, Fig. 1) 1.125-1.24 mm. In slide-mounted specimens, scape, excluding radicle, $2.9-3.0 \times$ as long as wide, clava 3.0-3.5 $\times$ as long as wide.

AnTEnNA. Clava white to very light yellow.

Mesosoma. Propodeum either without a distinct median carina or with a short median carina extending from posterior margin for about one-third to half length.

Wings. Fore wing $4.9-5.0 \times$ as long as wide, longest marginal seta about $0.8 \times$ greatest width of fore wing.

Genitalia. Ovipositor $0.8-0.9 \times$ length of metatibia.

Male (paratypes)

Measurements. Body length (critical point dried specimens, Fig. 4) $1.125-1.155 \mathrm{~mm}$.

Color. Head (Fig. 5A) black except face dark brown, rest of body (Fig. 3B) mostly brown except pronotum and petiole light brown and apical gastral terga dark brown; scape and pedicel light brown, flagellum brown; legs mostly light brown except metatibia slightly darker.

Mesosoma. Propodeum without a median carina.

WINGS. Fore wing (Fig. 5D) $1.568 \mathrm{~mm}$ long, $4.5 \times$ as long as wide, its longest marginal seta $0.9 \times$ greatest width of wing; hind wing (Fig. 5D) about $39 \times$ as long as wide, its longest marginal seta $6.7 \times$ greatest width of wing.

Antenna (Fig. 5C). $2.585 \mathrm{~mm}$ long, with scape smooth, $2.4 \times$ as long as wide excluding radicle, and much shorter than any funicular; F2 the longest and F6 the shortest funiculars.

Genitalia (Fig. 5B). $0.23 \mathrm{~mm}$ long. 
Ganomymar dessarti De Santis, 1972

Figs 6-7

Ganomymar dessarti De Santis, 1972: 2-3 (type locality: unknown, except being in Madagascar (De Santis 1972)). Holotype female [RBINS], dry-mounted except for one antenna and one fore wing mounted on a slide in Faure's liquid (De Santis 1972), examined during a visit in June 1997.

\section{Diagnosis}

Ganomymar dessarti is a member of the dessarti species group. Females differ from those of G. libertatium by the diagnostic features given in the key.

\section{Material examined}

MADAGASCAR - 1 \& (on slide); Alaotra-Mangoro Region [formerly within Toamasina Province], Andasibe-Mantadia National Park; "MADAGASCAR: Toamasina Prov. Parc National Mantadia $18^{\circ} 47.5^{\prime} \mathrm{S}, 48^{\circ} 25.6^{\prime} \mathrm{E}, 895 \mathrm{~m}$ 25-28.xi.1998, H. J. Ratsirarson (\#111). Sifted litter (leaf mold, rotten wood), rainforest CAS LOT \# 014698"; CAS.

\section{Redescription}

Female (non-type specimen)

CoLor. Head black, rest of body (Fig. 6A-B) mostly light brown; scape and pedicel light brown, funicle brown, clava white; legs light brown except metacoxa and metatrochanter pale.

HEAD (Fig. 6C). Large, $1.35 \times$ as wide as mesosoma. Face smooth and with fine, inconspicuous setae below toruli; toruli raised above face surface, in dorsal view projecting forward and in lateral view the anteriormost point on the head; vertex smooth, with 4 or 5 pairs of short, strong setae.

Antenna (Fig. 6E). Scape, excluding radicle, $2.7 \times$ as long as wide; pedicel smooth, longer than $\mathrm{F} 1$ and $1.5 \times$ as long as wide; F5 as long as F6, length to width ratios of funiculars: $\mathrm{F} 1=2.1, \mathrm{~F} 2=6.4 ; \mathrm{F} 3=4.9$; $\mathrm{F} 4=3.3 ; \mathrm{F} 5=2.3 ; \mathrm{F} 6=1.9$; clava $2.8 \times$ as long as wide, longer than combined length of 3 preceding flagellomeres.

Mesosoma (Fig. 6D). About $1.9 \times$ as long as wide, with mesoscutum except at anterior margin, scutellum + frenum, and metanotum reticulate, with sculpture on mesoscutum mesh-like, on scutellum and metanotum longitudinal, otherwise smooth; pronotum almost entire but with very short mediolongitudinal groove anteriorly, with 2 pairs of strong setae at posterior margin; axillar seta $0.05 \mathrm{~mm}$ long; scutellum + frenum a little longer than mesoscutum, scutellum not divided mediolongitudinally, with campaniform sensilla very close to its posterior margin; propodeum (Fig. 7A) with prominent, widely separated, subparallel, almost complete submedian carinae and area between them raised anteromedially (best observed in lateral view, Fig. 6B).

Wings. Brachypterous. Fore wing (Fig. 7C) lanceolate and slightly, longitudinally folded apically (i.e., not quite flat) (Fig. 6A-B), $7.1 \times$ as long as wide, extending far beyond apex of gaster (Fig. 6A-B); marginal vein with 1 dorsal macrochaeta; disc strongly infumate, with discal setae originating behind apex of submarginal vein and densely setose beyond venation; fringe setae short and reduced, those on anterior margin markedly thicker than on posterior margin, longest marginal seta $0.27 \times$ greatest width of wing. Hind wings (Fig. 7D) of different length and degree of brachyptery, one about $25 \times$ and the other $17.5 \times$ as long as wide; disc strongly infumate, fringe setae few and reduced.

LEGS. All legs smooth, metacoxa with dense white setae. 

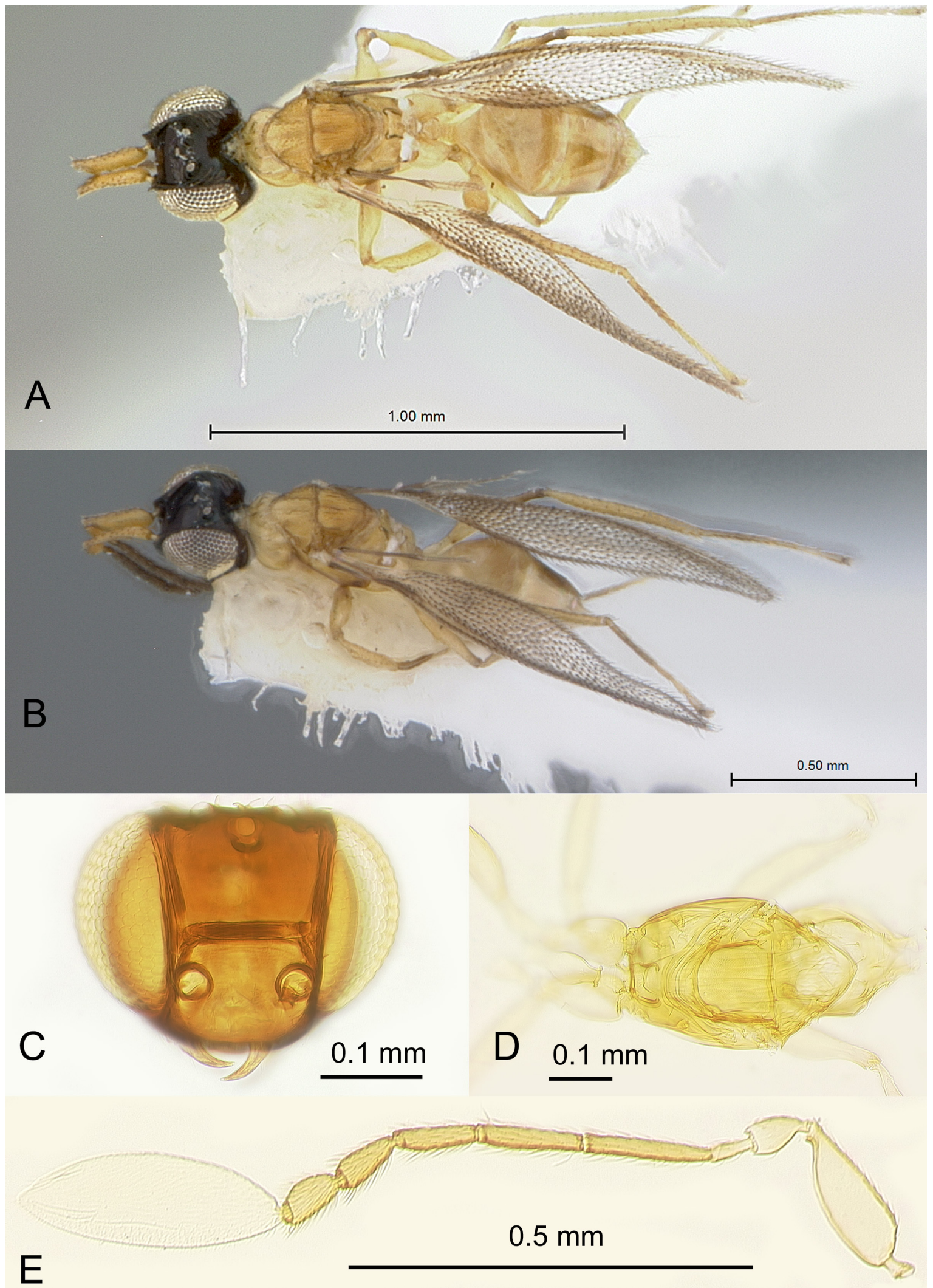

Fig. 6. Ganomymar dessarti De Santis, 1972, non-type, $q$, (CASENT 2079165), Andasibe-Mantadia National Park, Alaotra-Mangoro Region, Madagascar. A. Habitus in dorsal view. B. Habitus in dorsolateral view. C. Head in frontal view. D. Mesosoma. E. Antenna. 
Metasoma. Petiole (Fig. 7A) smooth, $2.4 \times$ as long as wide and swollen medially, a little shorter than metacoxa. Ovipositor 0.85 length of gaster (Fig. 7B), not exserted beyond its apex, about $1.2 \times$ length of mesotibia and about as long as metatibia.

MEAsurements $(\mu \mathrm{m})$. Body (of the critical point dried specimen prior to slide-mounting) $=1190$; head (of the critical point dried specimen prior to slide-mounting) $=232$; mesosoma $=455$; mesoscutum $=130$; scutellum $=150$; petiole $=123$; gaster $=535$; ovipositor $=445$. Radicle $=28$; rest of scape $=188$; pedicel $=72 ; F 1=48 ; F 2=151 ; F 3=127 ; F 4=100 ; F 5=75 ; F 6=75$; clava $=322$. Fore $w i n g=1246: 175$; venation $=297$; longest marginal seta $=48$. Hind wing $=527: 21(421: 24)$; longest marginal seta $=45$. Mesotibia $=381$; metatibia $=436$.

\section{Male}

Unknown.

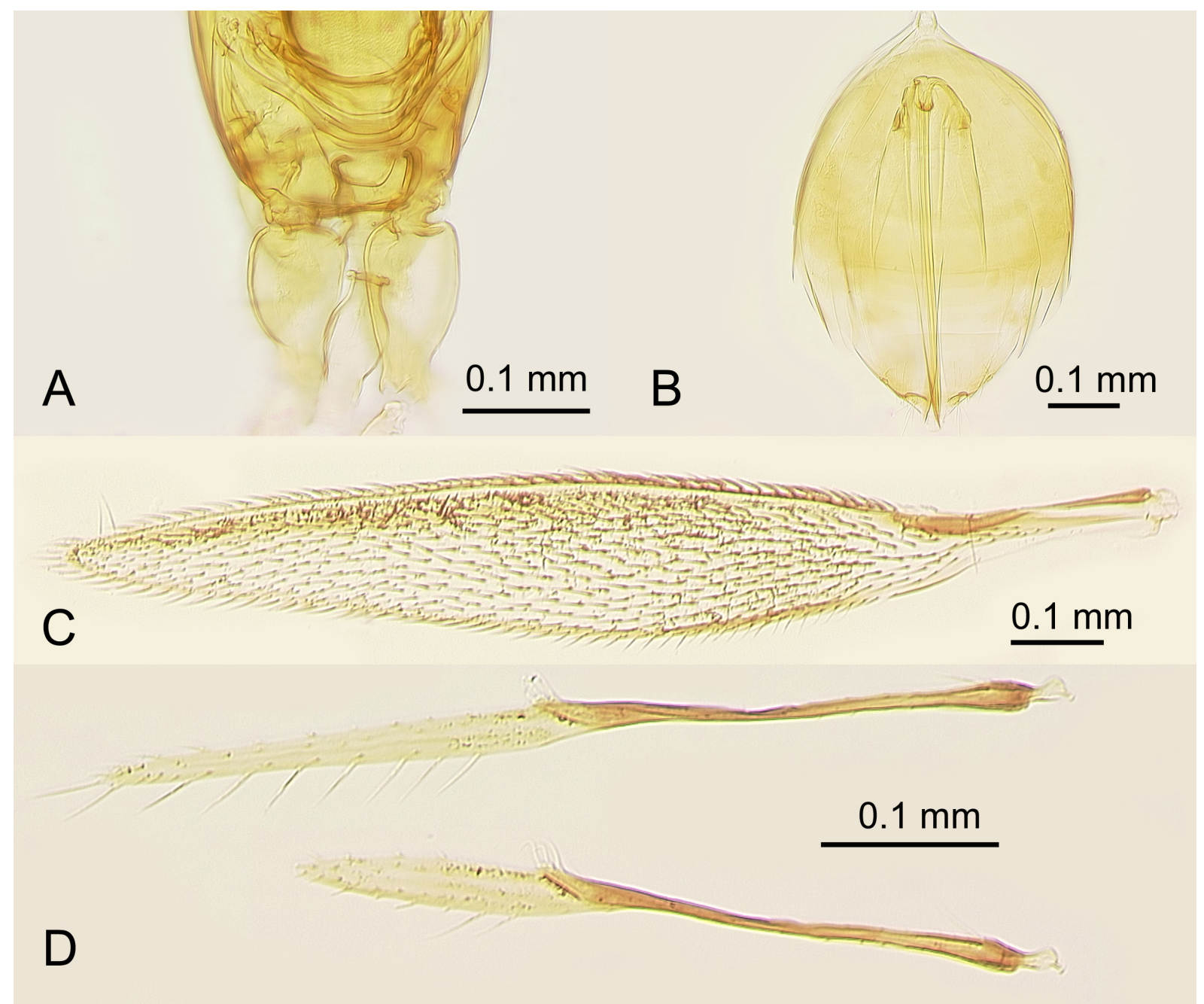

Fig. 7. Ganomymar dessarti De Santis, 1972, non-type, + , (CASENT 2079165), Andasibe-Mantadia National Park, Alaotra-Mangoro Region, Madagascar. A. Propodeum and petiole. B. Gaster. C. Fore wing. D. Hind wings. 
Ganomymar libertatium sp. nov.

urn:1sid:zoobank.org:act:5624D0AD-51CE-48DC-890C-E0F47C5E187E

Figs $8-12$

\section{Diagnosis}

Ganomymar libertatium is a member dessarti species group. Its female differs from the other member of this group, G. dessarti, by the diagnostic features given in the key.

\section{Etymology}

The species epithet refers to Libertatia, a legendary free colony in Madagascar in the late $17^{\text {th }}$ century.

\section{Type Material}

\section{Holotype}

MADAGASCAR - $q$ (on slide, missing one hind wing and dissected under 4 coverslips) [Fig. 8A]; Sava Region [formerly within Antsiranana Province], Fôret de Binara; "MADAGASCAR: Antsiranana

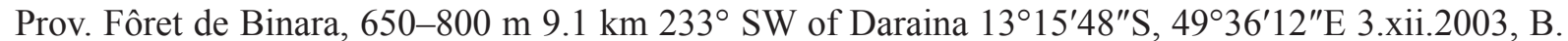
Fisher, sifted litter (leaf mold, rotten wood), rainforest BLF9656, CAS LOT \# 014720", "Mounted at UCR/ERM by V. V. Berezovskiy 2012 in Canada balsam", [red] "Ganomymar libertatium Triapitsyn HOLOTYPE + ”, “Det. by S. V. Triapitsyn 2012”; CAS.

\section{Paratype}

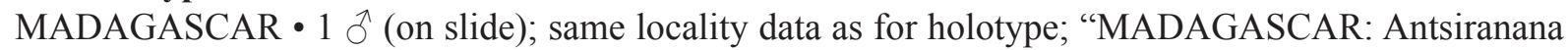

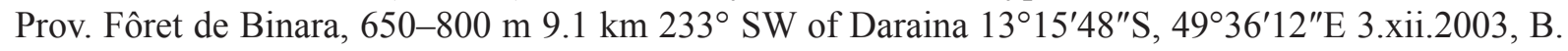
Fisher, YPT rainfor.[est] BLF9657, CAS LOT \# 014721"; CAS.

\section{Description}

\section{Female (holotype)}

Color. Head and rest of body (Fig. 9C) mostly whitish to very light brown with brownish suffusions on vertex, mesoscutum, and middle of scutellum, except trabeculae dark brown and mesopleuron with brown spot at lower margin; scape and F1 whitish, pedicel light brown, F2-F6 brown, clava white; legs whitish.

HEAD (Fig. 8B, E). Large, $1.3 \times$ as wide as mesosoma; face smooth, with fine, inconspicuous setae below toruli; toruli raised a little above face surface and slightly projecting forward, rest of head strongly reticulate; vertex with several pairs of short setae.

AnTENNA (Fig. 8D). Scape $2.6 \times$ as long as wide excluding radicle; pedicel smooth, longer than F1 and $1.7 \times$ as long as wide; F5 as long as F6, length to width ratios of funiculars: F1 = 2.2, F2 = 5.3; $\mathrm{F} 3=3.8 ; \mathrm{F} 4=2.6 ; \mathrm{F} 5=1.9 ; \mathrm{F} 6=1.5 ;$ clava $3.0 \times$ as long as wide, almost as long as combined length of 4 preceding flagellomeres.

Mesosoma (Fig. 8B-C, E). Smooth, about $1.9 \times$ as long as wide; pronotum, mesoscutum except along anterior margin, scutellum, frenum, and metanotum with reticulate sculpture; pronotum large, with 3 pairs of weak setae at posterior margin; axillar seta $0.024 \mathrm{~mm}$ long; scutellum + frenum longer than mesoscutum, scutellum not divided mediolongitudinally; propodeum (Fig. 8C) with prominent, widely separated submedian carinae extending almost to anterior margin.

Wings. Brachypterous. Fore wing (Fig. 9A) with pointed apex, 3.6 $\times$ as long as wide, extending a little beyond apex of gaster (Fig. 9C); marginal vein with 1 dorsal macrochaeta; disc infumate and with 2 brown bands, densely setose beyond venation, with the modified, very short and strong, discal setae 


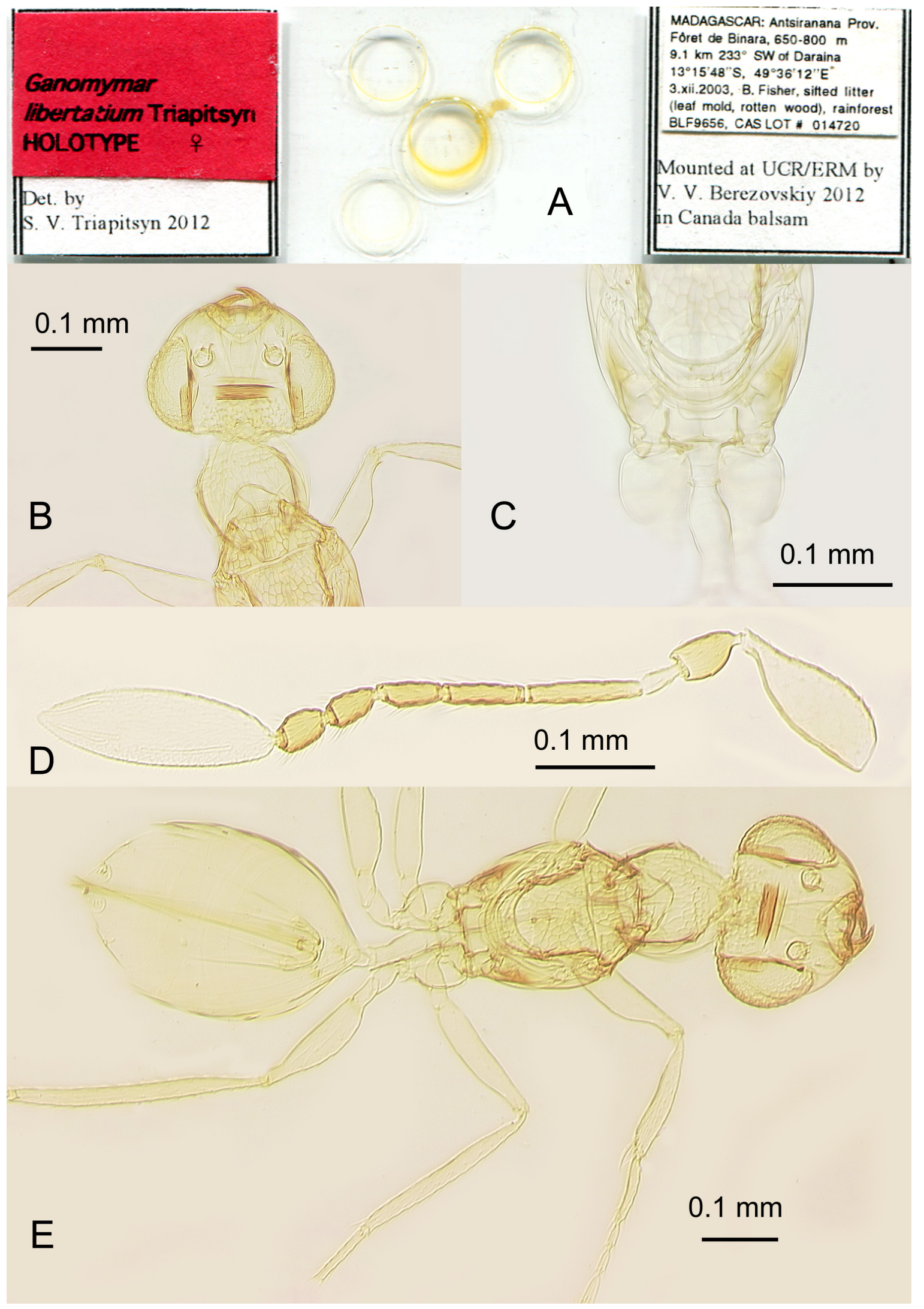

Fig. 8. Ganomymar libertatium sp. nov., + , holotype (CAS). A. Slide. B. Head, pronotum and mesoscutum. C. Scutellum, propodeum and petiole. D. Antenna. E. Body. 
originating behind apex of submarginal vein, with numerous round 'cells' beyond venation; longest marginal seta $0.15 \times$ greatest width of wing, proximal fringe setae on anterior margin much thicker than other fringe setae. Hind wing (Fig. 9B) strongly reduced, almost without membrane and setae.

LEGS. All legs smooth, metacoxa with sparse white setae.

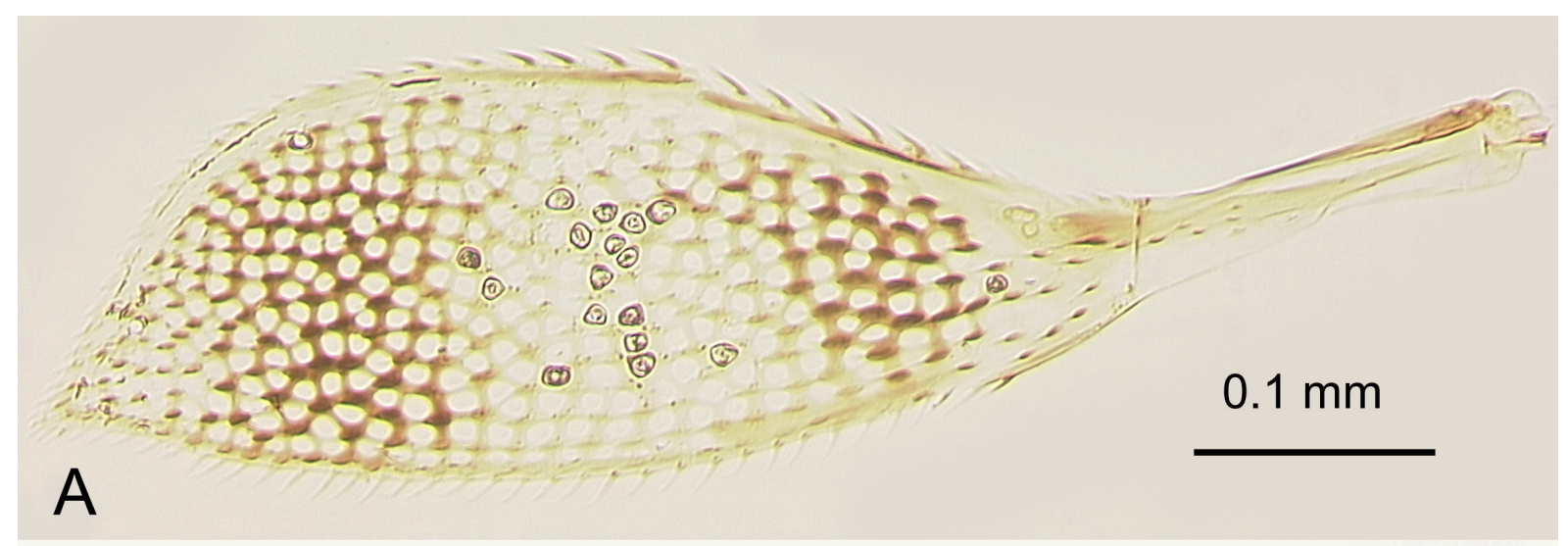

B

\section{$0.1 \mathrm{~mm}$}

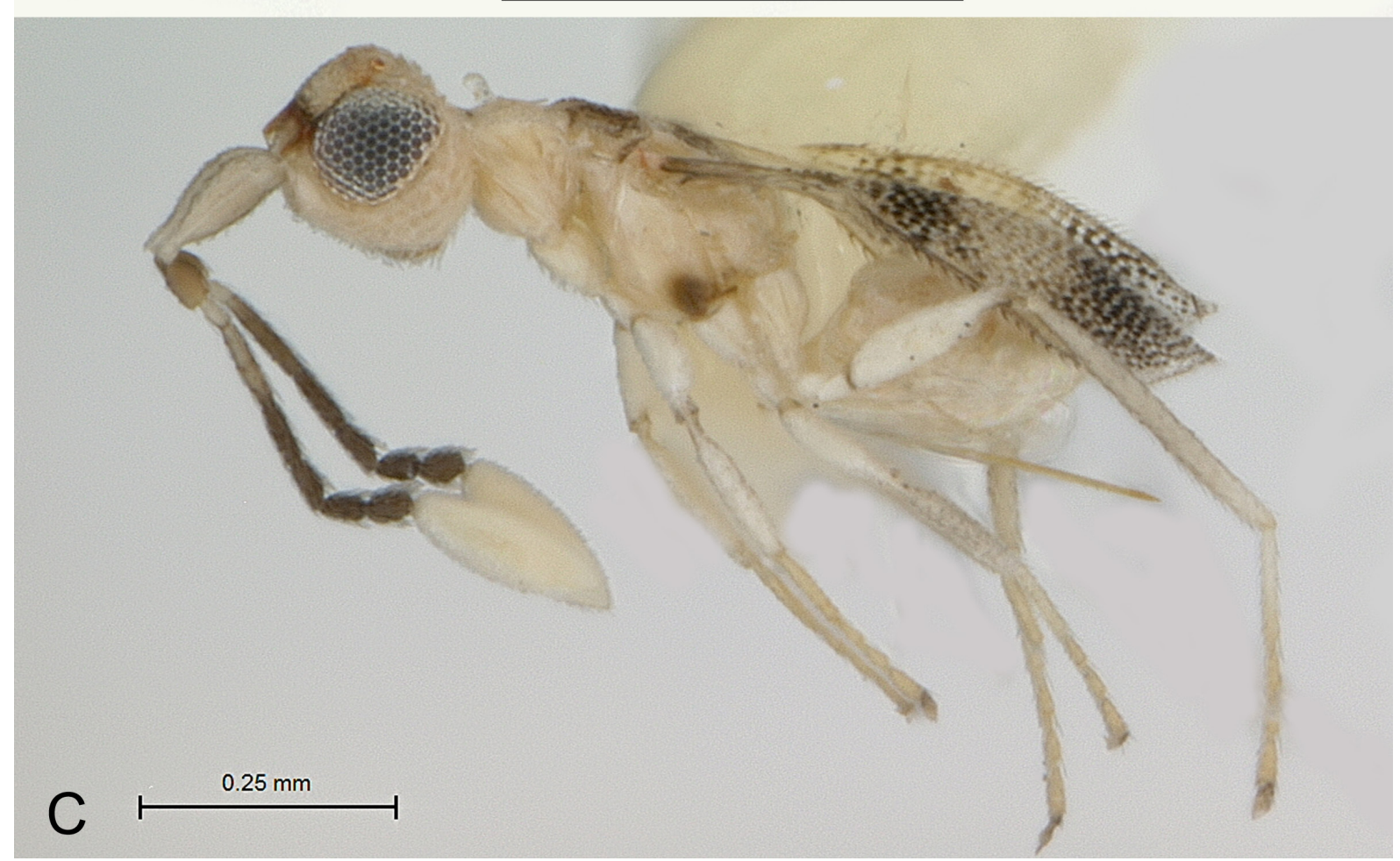

Fig. 9. Ganomymar libertatium sp. nov., $q$, holotype (CAS). A. Fore wing. B. Hind wing. C. Habitus in lateral view (prior to slide-mounting). 
Metasoma. Petiole (Fig. 8C) smooth, $2.5 \times$ as long as wide and slightly swollen medially, a little longer than metacoxa. Ovipositor $0.85 \times$ length of gaster (Fig. $8 \mathrm{E}$ ), barely exserted beyond its apex, $1.4 \times$ length of mesotibia and about $1.1 \times$ length of metatibia.

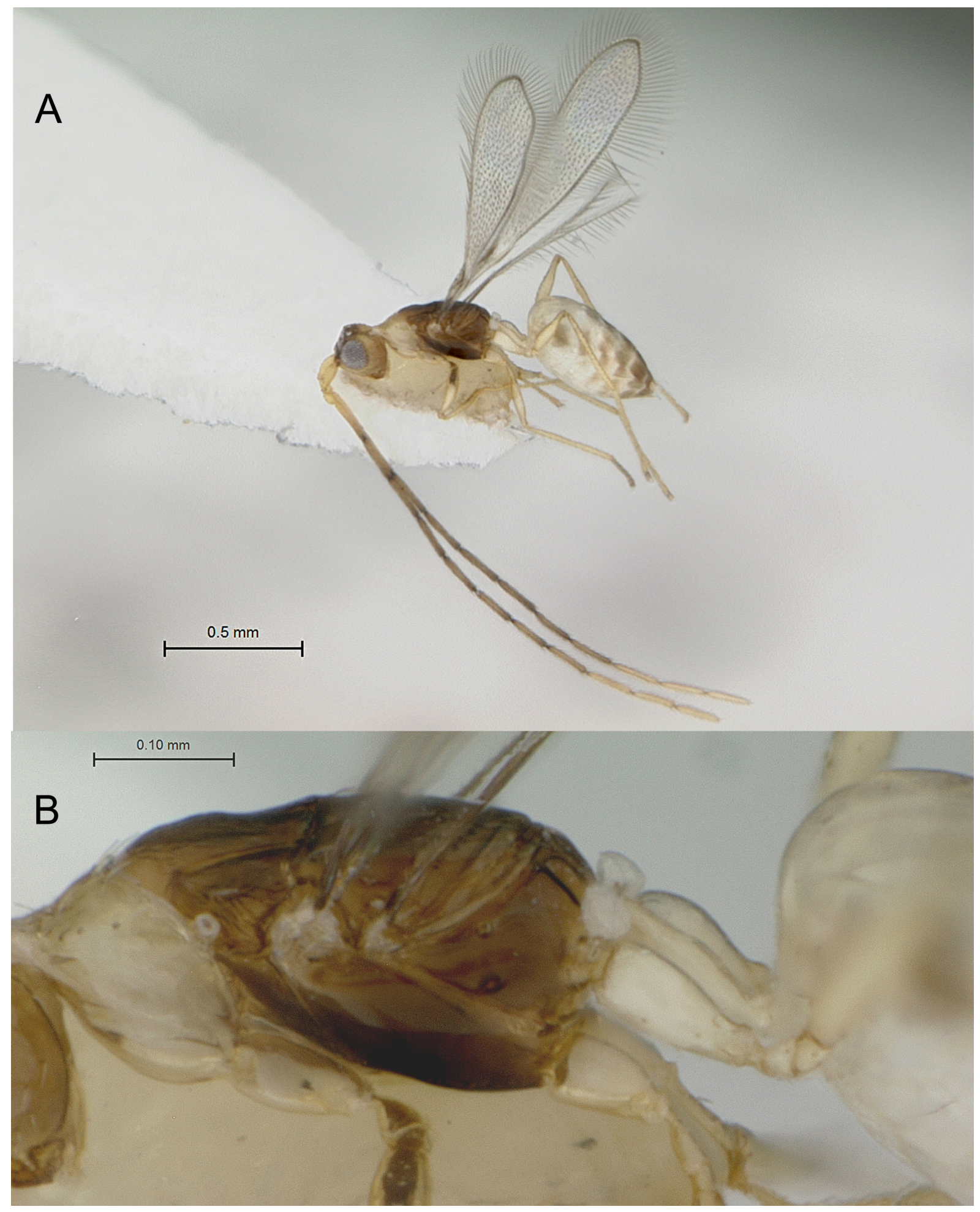

Fig. 10. Ganomymar libertatium sp. nov., Ô, paratype (CAS), prior to slide-mounting. A. Habitus in lateral view. B. Mesosoma and petiole in lateral view. 


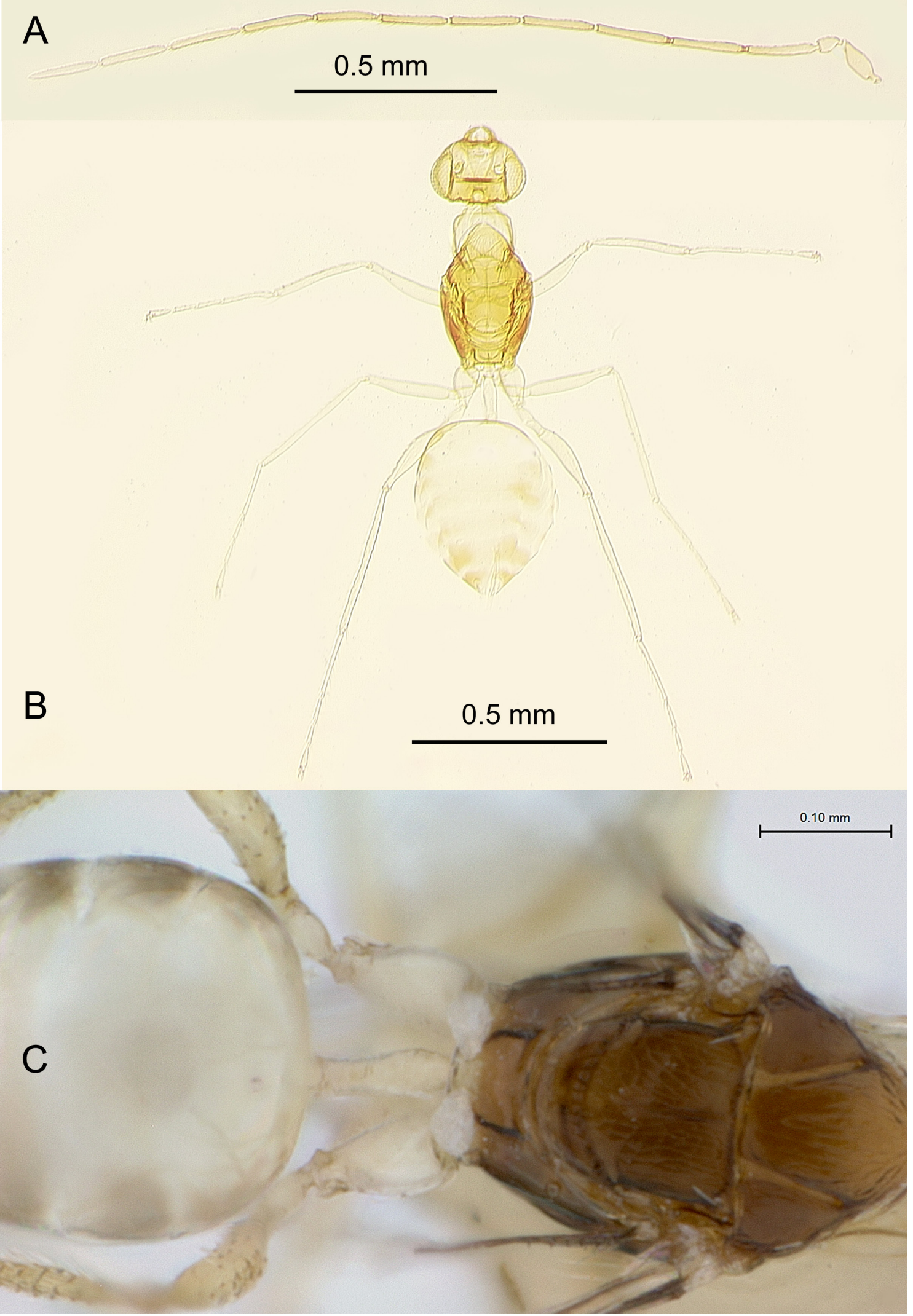

Fig. 11. Ganomymar libertatium sp. nov., $\widehat{\jmath}$, paratype (CAS). A. Antenna. B. Body and legs. C. Mesosoma, petiole and base of gaster in dorsal view (prior to slide-mounting). 
Measurements $(\mu \mathrm{m})$. Body (critical point dried specimen prior to slide-mounting) $=925$; head (critical point dried specimen prior to slide-mounting) $=170$; mesosoma $=364$; mesoscutum $=103$; scutellum $=121$; petiole $=91 ;$ gaster $=382$; ovipositor $=342$. Radicle $=13$; rest of scape $=149$; pedicel $=58 ; \mathrm{F} 1=33 ; \mathrm{F} 2=97 ; \mathrm{F} 3=70 ; \mathrm{F} 4=55 ; \mathrm{F} 5=44 ; \mathrm{F} 6=44$; clava $=203$. Fore $w i n g=588: 165$; venation $=203$; longest marginal seta $=24$. Hind wing $=227: 9$. Mesotibia $=248 ;$ metatibia $=324$.

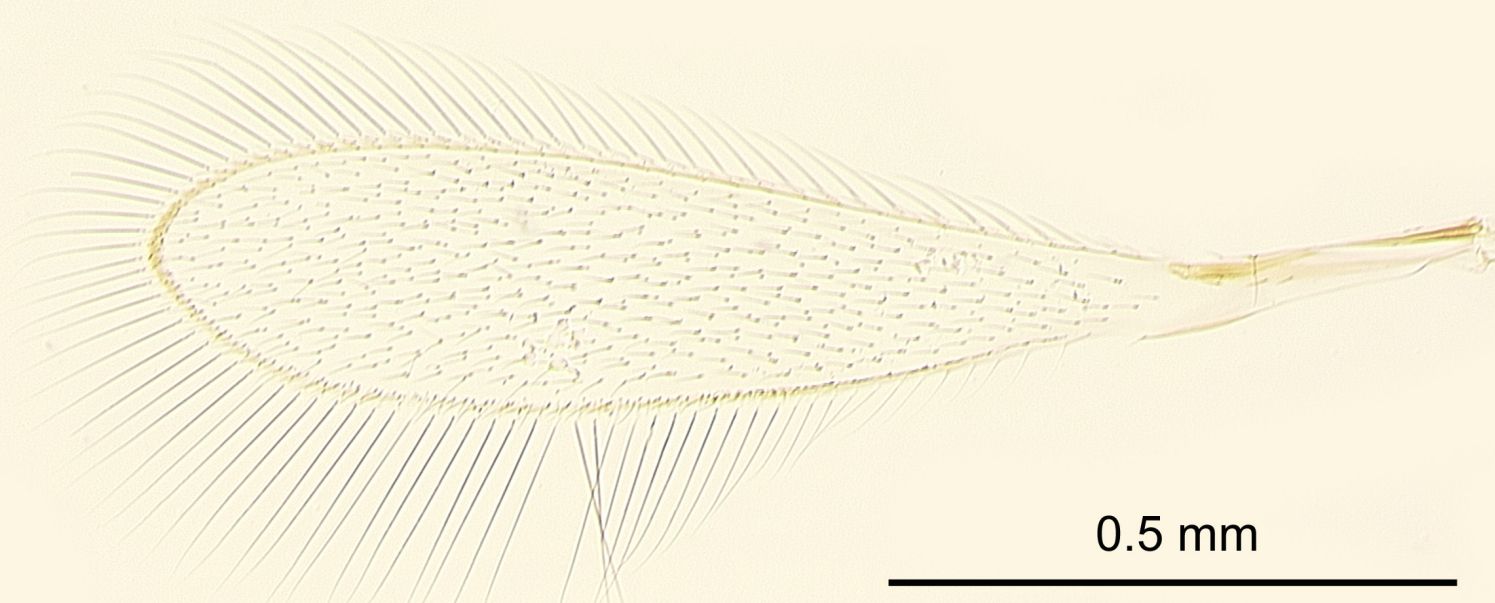

A

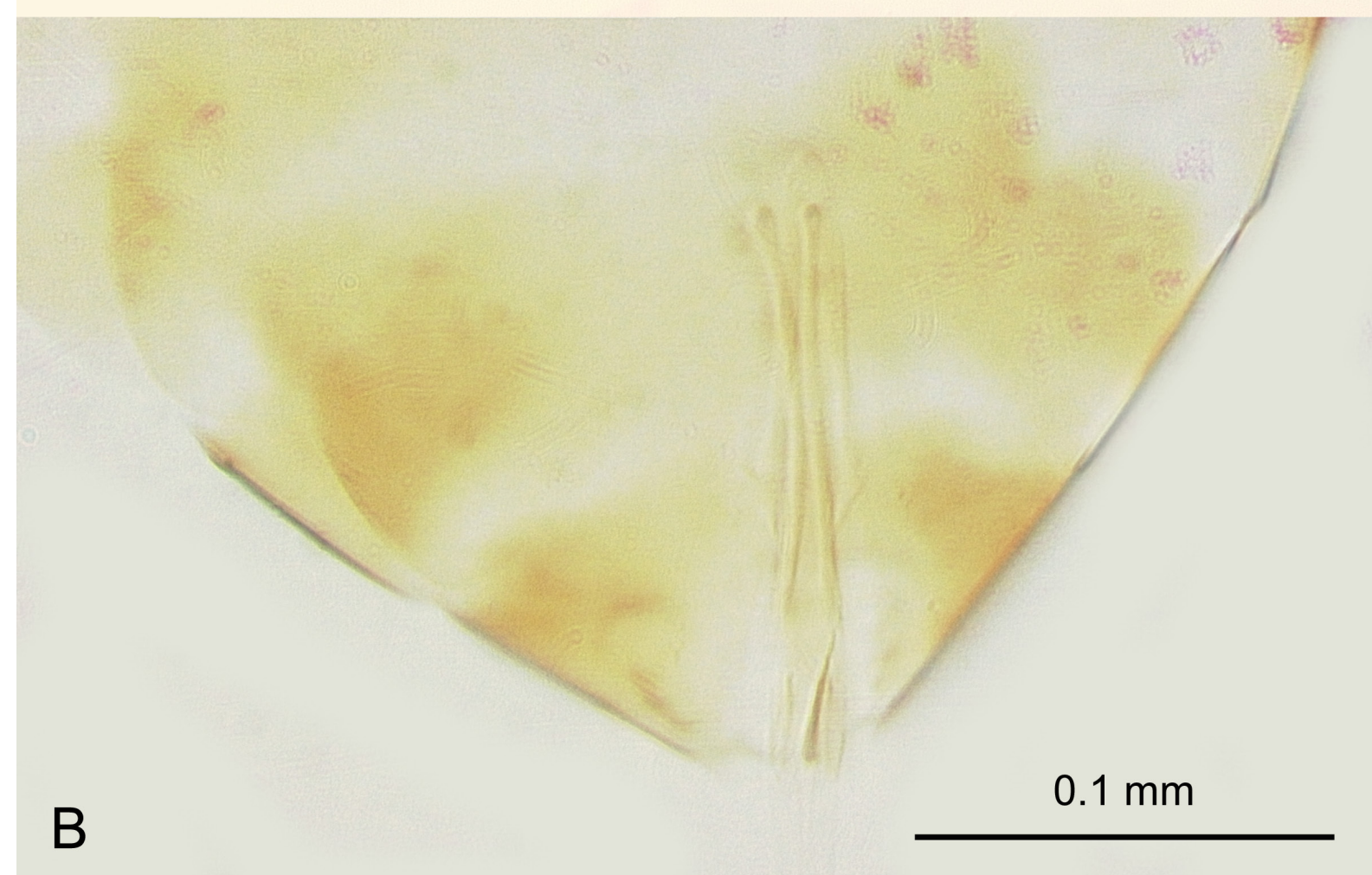

Fig. 12. Ganomymar libertatium sp. nov., §̂, paratype (CAS). A. Fore and hind wings. B. Genitalia. 
Male (paratype, Figs 10A, 11B)

This species displays a particularly remarkable sexual dimorphism (Figs 9C, 10A).

Measurements. Body length (of the critical point dried specimen prior to slide-mounting) $1.125 \mathrm{~mm}$, head length (of the critical point dried specimen prior to slide-mounting) $0.165 \mathrm{~mm}$.

CoLOR. Head mostly brown except face and occiput light brown and trabeculae dark brown; pronotum yellowish dorsally and pale laterally, remainder of mesosoma brown; petiole whitish, gaster mostly whitish basally and brownish laterally and apically; scape and pedicel pale light brown, flagellum brown except F9-F11 white (F9 less so than following flagellomeres); legs mostly whitish to pale light brown except pro- and mesocoxae partially and metacoxa entirely white.

Mesosoma. Vertex smooth. Mesosoma smooth except mesoscutum partially with mesh-like longitudinal sculpture; pronotum not enlarged, much shorter than in female; scutellum almost completely (except posteriorly) divided mediolongitudinally by a narrow groove; propodeum (Figs 10B, 11C) with submedian carinae as in female.

WINGS. Macropterous; fore wing (Fig. 12A) $1.206 \mathrm{~mm}$ long, $4.9 \times$ as long as wide, marginal vein with 2 dorsal macrochaetae, disc without round 'cells', with 3 or 4 setae behind apex of submarginal vein, bare just beyond venation and densely setose elsewhere, discal microtrichia normal, long, longest marginal seta a little more than $0.9 \times$ greatest width of wing; hind wing (Fig. 12A) about $32 \times$ as long as wide, with membrane narrow, its longest marginal seta $5.5 \times$ greatest width of wing.

Metasoma. Petiole dorsally with a few inconspicuous cross-ridges.

AntenNA (Fig. 11A). $2.155 \mathrm{~mm}$ long, with scape smooth, $2.5 \times$ as long as wide excluding radicle, and much shorter than any funicular; all funiculars subequal in length except F6 and F7 slightly shorter.

Genitalia (Fig. 12B). $0.173 \mathrm{~mm}$ long.

Ganomymar zuparkoi sp. nov. urn:1sid:zoobank.org:act:81128114-729C-4B04-8C41-F73141F14184

Figs 13-15

\section{Diagnosis}

Ganomymar zuparkoi is a member of the caslot species group. Female differs from the other species of this group, G. caslot, by the diagnostic features given in the key.

\section{Etymology}

This species is named after Robert L. Zuparko who sorted numerous interesting Mymaridae from B.L. Fisher's project Madagascar samples at CAS and loaned them to me.

\section{Type Material}

\section{Holotype}

MADAGASCAR - $q$ (on slide, missing one pair of wings and dissected under 4 coverslip) [Fig. 14A]; Ihorombe Region [formerly within Fianarantsoa Province], 8.0 km NE of Ivohibe; "MADG'R: Prov.

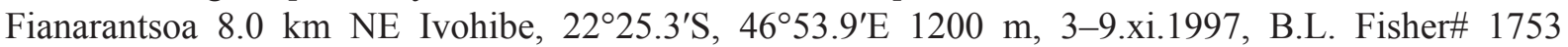
[additional numbers crossed over]", "sifted litter (leaf mold, rotten wood) montane rainforest", "CAS ENT 2000491", "Mounted at UCR/ERM by V. V. Berezovskiy 2012 in Canada balsam", [red] "Ganomymar zuparkoi Triapitsyn HOLOTYPE @”, "Det. by S. V. Triapitsyn 2012”; CAS. 


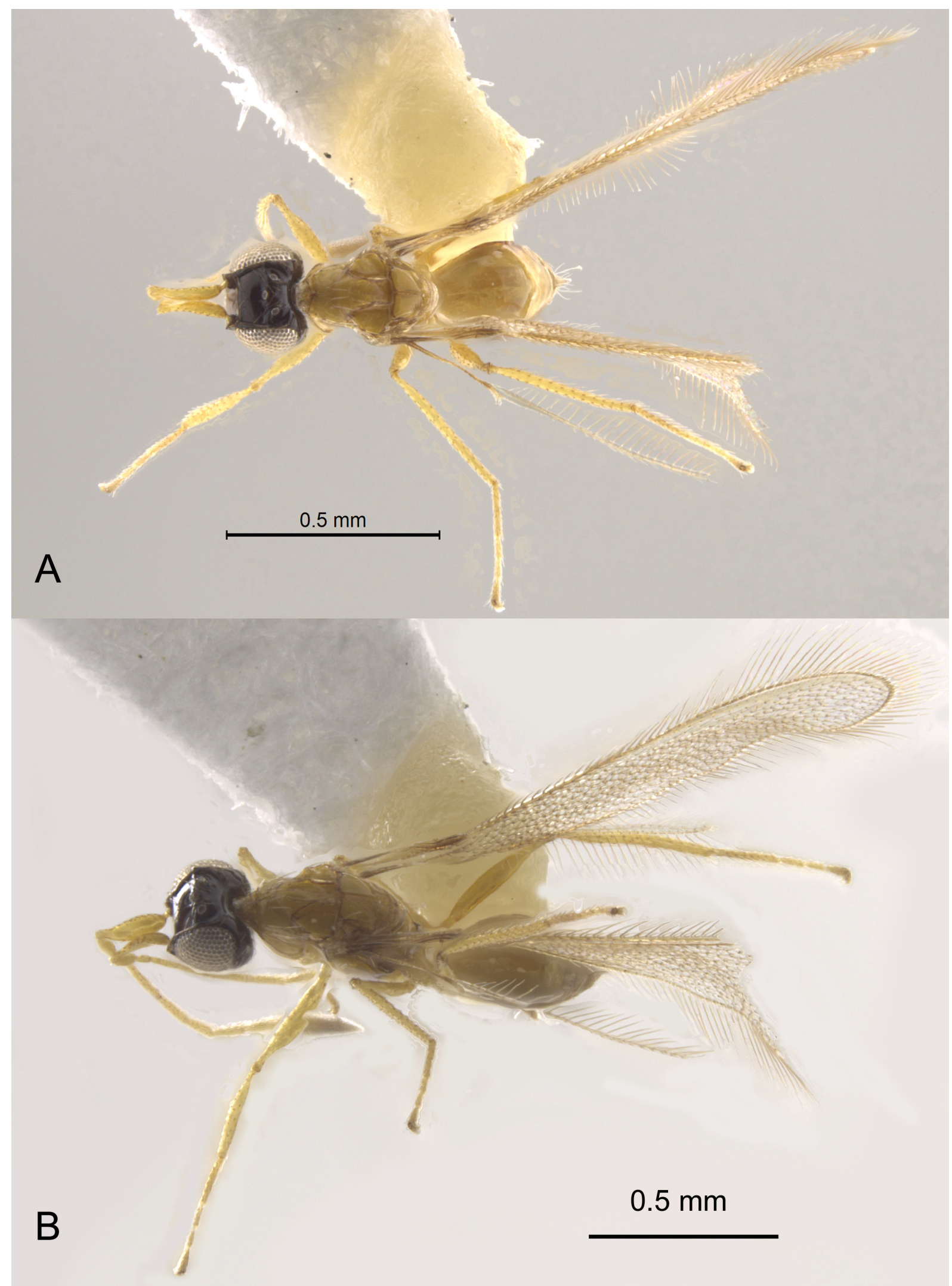

Fig. 13. Ganomymar zuparkoi sp. nov., + , paratype (CAS). A. Habitus in dorsal view. B. Habitus in dorsolateral view. 

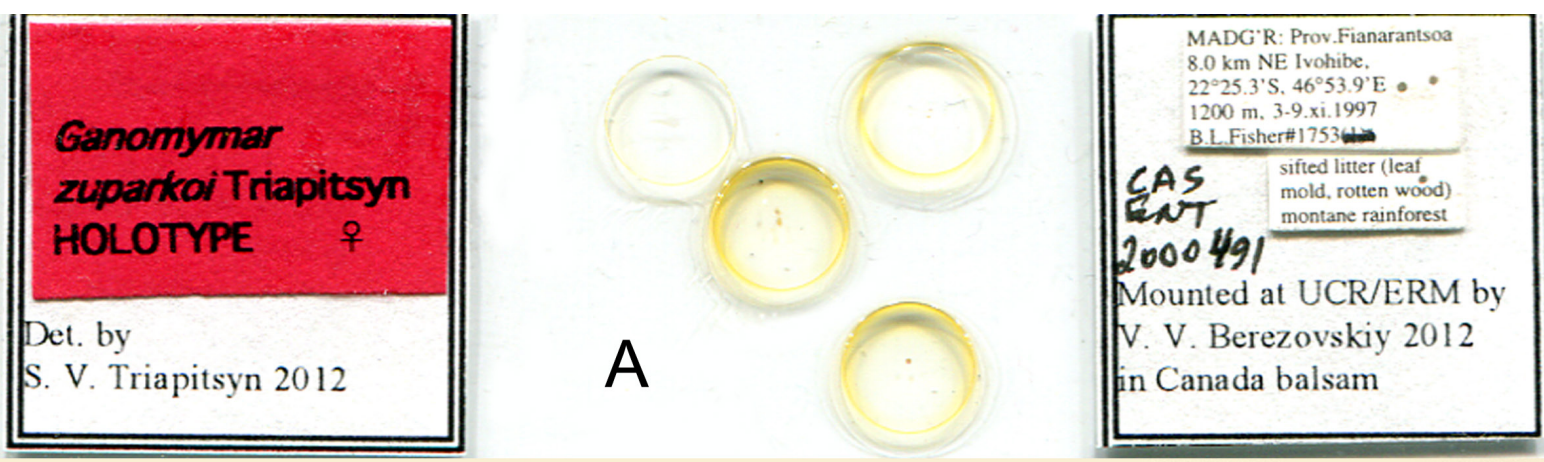

B
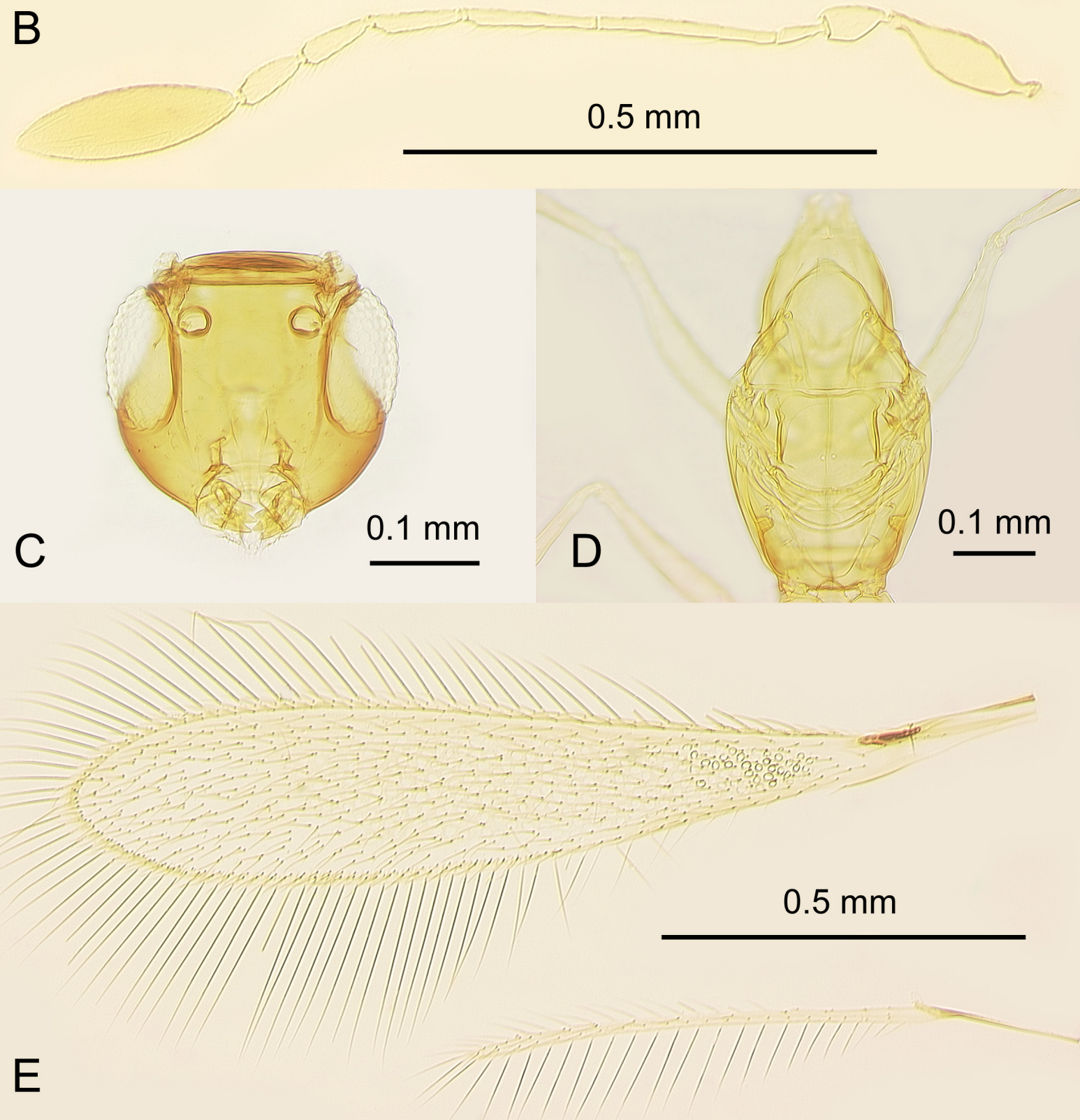

Fig. 14. Ganomymar zuparkoi sp. nov., + , holotype (CAS). A. Slide. B. Antenna. C. Head in frontal view. D. Mesosoma. E. Fore and hind wings. 


\section{Paratype}

MADAGASCAR 1 i (on point); Haute Matsiatra Region, Andringitra National Park, 43 km South

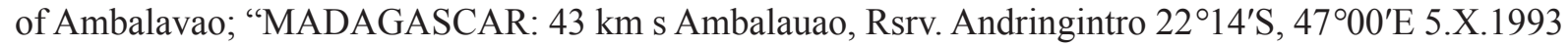
825m BLFisher\#747 (1)"; CAS.

\section{Description}

\section{Female (holotype)}

CoLOR. Head very dark brown, rest of body yellow to light brown except mesopleura and gaster partially brown; antenna yellow except clava brown; legs light brown.

HeAD (Fig. 14C). Slightly wider than high and $1.1 \times$ as wide as mesosoma; face smooth, with fine, inconspicuous setae below toruli; vertex smooth; occiput with 2 pairs of setae.

Antenna (Fig. 14B). Scape, excluding radicle, $2.9 \times$ as long as wide; pedicel smooth, longer than $\mathrm{F} 1$ and $1.8 \times$ as long as wide; F5 about as long as F6, length to width ratios of funiculars: F1 $=2.6, \mathrm{~F} 2=11.1$; $\mathrm{F} 3=7.8 ; \mathrm{F} 4=4.6 ; \mathrm{F} 5=3.1 ; \mathrm{F} 6=2.4$; clava $3.2 \times$ as long as wide, almost as long as combined length of 3 preceding flagellomeres.

Mesosoma (Figs 14D, 15). Smooth, about $1.9 \times$ as long as wide; pronotum with 2 pairs of strong setae at posterior margin; axillar seta $0.045 \mathrm{~mm}$ long, not extending to campaniform sensilla; scutellum + frenum a little shorter than mesoscutum, scutellum almost completely divided mediolongitudinally

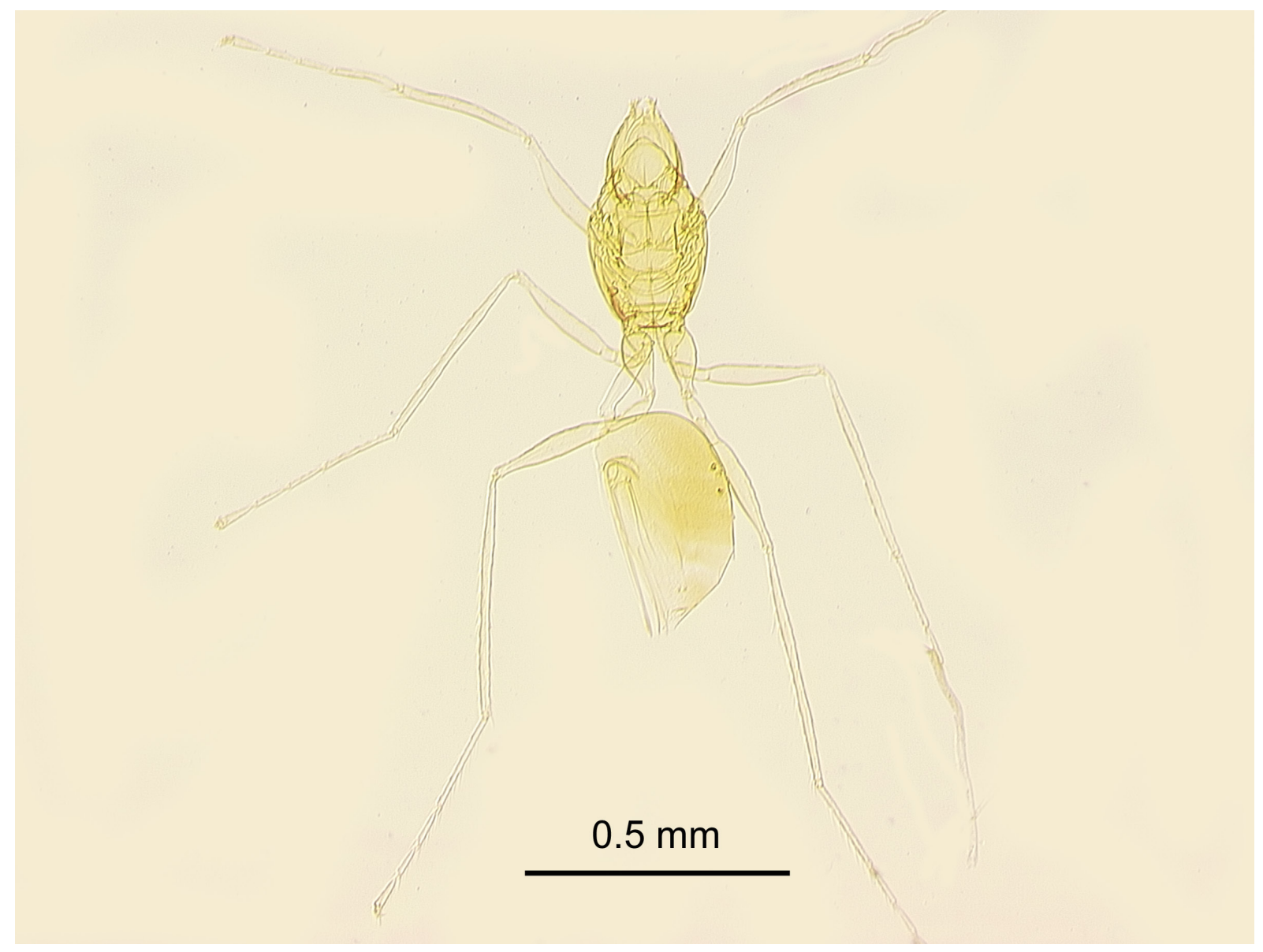

Fig. 15. Ganomymar zuparkoi sp. nov.,, , holotype (CAS). Mesosoma, metasoma and legs. 
by groove (except at posterior margin); propodeum with short, weak median carina extending from posterior margin for about one-third length.

Wings. Macropterous. Fore wing (Fig. 14E) $5.4 \times$ as long as wide; marginal vein with 1 dorsal macrochaeta; disc slightly infumate, densely setose beyond venation, the discal setae originating behind apex of submarginal vein, with numerous round 'cells' beyond venation particularly conspicuous up to about $0.8 \times$ length of wing and not visible at wing's apex; longest marginal seta about $1.1 \times$ greatest width of wing, proximal fringe setae on anterior margin thicker than other fringe setae. Hind wing (Fig. 14E) about $42 \times$ as long as wide; disc slightly infumate, with 2 rows of setae; longest marginal seta $7.3 \times$ greatest width of wing.

LEGS. All legs smooth, metacoxa with white setae.

Metasoma. Petiole (Fig. 15) smooth, $4.7 \times$ as long as wide and slightly widened medially, a little longer than metacoxa. Ovipositor about $0.8 \times$ length of gaster (Fig. 15), not exserted beyond its apex, about $0.9 \times$ length of mesotibia and almost $0.8 \times$ length of metatibia.

MEAsurements $(\mu \mathrm{m})$. Body (of the critical point dried specimen prior to slide-mounting) $=1040$; head (of the critical point dried specimen prior to slide-mounting $)=180$; mesosoma $=430$; mesoscutum $=140$; scutellum $=133$; petiole $=157$; gaster $=424$; ovipositor $=354$. Radicle $=27$; rest of scape $=149$; pedicel $=67 ; \mathrm{F} 1=39 ; \mathrm{F} 2=183 ; \mathrm{F} 3=139 ; \mathrm{F} 4=94 ; \mathrm{F} 5=75 ; \mathrm{F} 6=72 ;$ clava $=233$. Fore wing $=1359: 251$; venation $=264$; longest marginal seta $=285$. Hind wing $=879: 21$; longest marginal seta $=154$. Mesotibia $=379 ;$ metatibia $=454$.

Female (paratype, Fig. 13)

Body length (critical point dried, point-mounted specimen) $1.09 \mathrm{~mm}$.

\section{Male \\ Unknown.}

\section{Discussion}

The peculiar fore wings of females of species of Ganomymar, some of which are at least somewhat reduced (Figs 7C, 9A) or having characteristic numerous round 'cells' beyond venation (Figs 3A, 9A, $14 \mathrm{E}$ ), possibly have something to do with the habitats of their unknown hosts that may lay eggs in leaf litter in montane and other reinforests in Madagascar. Indeed, most of the specimens borrowed from CAS were collected either by sifting litter (leaf mold, rotten wood, etc.) or by using pitfall or yellow pan traps. Squeezing through leaf litter and wood debris while searching for host eggs with large, normal wings could lead to their damage in females. Possibly, the numerous round 'cells' on the fore wings of three of the four known species of Ganomymar (these are not evident in G. dessarti which has reduced and very narrow, slightly convex, with a longitudinal apical fold, fore wings, Figs 6A-B, 7C) could thus be a reinforcement structure for the otherwise delicate wing membrane. Although the narrow, apically pointed fore wing of females of $G$. dessarti is somewhat similar in shape to those of some species of Cremnomymar from the Juan Fernández Islands (Chile) (illustrated in Huber 2013), apparently, the reduction in $G$. dessarti is not related to that common among fairyflies from small island and high altitude habitats with windy conditions. As noted by Huber (2013), wing reductions, such as brachyptery or aptery, usually occur where there is a strong selection pressure against having fully developed wings. In the case of females of species of Ganomymar, we can observe a gradation from the two macropterous species from the caslot species group (G. caslot and G. zuparkoi) to the two moderately brachypterous species from the dessarti species group ( $G$. dessarti and $G$. libertatium). Interestingly, brachyptery in females of the latter species group definitely correlates with a more reticulate head and mesosoma, at 
least slightly projected forward toruli, and prominent submedian carinae on the propodeum whereas the two macropterous members of the former species group have more normally shaped heads, smooth mesosomata, and the propodeum is either without or with a short, rather weak median carina. At the same time, males, which are only known for G. caslot and G. libertatium, are macropterous, unlike the brachypterous males of some species of Cremnomymar, as illustrated in Huber (2013). That is indicative of the selective pressure for brachyptery in females coming from the leaf litter and wood debris on large island habitats for species of Ganomymar versus windy, small island habitats for species of Cremnomymar that affect both sexes.

\section{Acknowledgments}

I thank Robert L. Zuparko (CAS) for the loan of numerous ethanol-preserved Mymaridae from Madagascar and Vladimir V. Berezovskiy (UCRC) for mounting specimens. Jennifer Walker (UCRC) had taken some digital images of the dry-mounted specimens before they were slide-mounted. Simon van Noort (Iziko Museums of South Africa, Cape Town, South Africa) and an anonymous reviewer made many useful suggestions that improved the manuscript.

\section{References}

De Santis L. 1972. Nouveau genre et nouvelle espèce de Mymaridae Malgaches (Hymenoptera: Chalcidoidea). Bulletin de l'Institut royal des Sciences naturelles de Belgique 48 (12): 1-3.

Gibson G.A.P. 1997. Chapter 2. Morphology and terminology. In: Gibson G.A.P., Huber J.T. \& Woolley J.B. (eds) Annotated Keys to the Genera of Nearctic Chalcidoidea (Hymenoptera): 16-44. NRC Research Press, Ottawa.

Huber J.T. 2013. Redescription of Mymarilla Westwood, new synonymies under Cremnomymar Ogloblin (Hymenoptera, Mymaridae) and discussion of unusual wings. ZooKeys 345: 47-72.

https://doi.org/10.3897/zookeys.345.6209

Lin N.-Q., Huber J.T. \& LaSalle J. 2007. The Australian genera of Mymaridae (Hymenoptera: Chalcidoidea). Zootaxa 1596: 1-111.

Manuscript received: 10 January 2021

Manuscript accepted: 1 May 2021

Published on: 1 July 2021

Topic editor: Nesrine Akkari

Section editor: Gavin R. Broad

Desk editor: Eva-Maria Levermann

Printed versions of all papers are also deposited in the libraries of the institutes that are members of the EJT consortium: Muséum national d'histoire naturelle, Paris, France; Meise Botanic Garden, Belgium; Royal Museum for Central Africa, Tervuren, Belgium; Royal Belgian Institute of Natural Sciences, Brussels, Belgium; Natural History Museum of Denmark, Copenhagen, Denmark; Naturalis Biodiversity Center, Leiden, the Netherlands; Museo Nacional de Ciencias Naturales-CSIC, Madrid, Spain; Real Jardín Botánico de Madrid CSIC, Spain; Zoological Research Museum Alexander Koenig, Bonn, Germany; National Museum, Prague, Czech Republic. 